\title{
Hormonally controlled ILC antigen presentation potential is reduced during pregnancy
}

\author{
Rebekka Einenkel, Jens Ehrhardt, Kristin Hartmann, Diana Krüger, Damián Oscar Muzzio and \\ Marek Zygmunt \\ Department of Obstetrics and Gynecology, University of Greifswald, Greifswald, Germany \\ Correspondence should be addressed to D O Muzzio; Email: damian.muzzio@med.uni-greifswald.de
}

\begin{abstract}
Strategically located in mucosal barriers, innate lymphoid cells (ILCs) are relevant in local containment and tolerance of commensal microflora. ILCs have been recently described at the fetomaternal interface, where the development of a semi-allogeneic fetus can only succeed in a well-controlled immune environment. We postulate that ILCs adapt their antigen presentation capacity to protect pregnancy from excessive immune responses. Human ILCs were studied in deciduae of term pregnancies, peripheral blood and in in vitro generated ILCs. Fresh isolated lymphocytes or cells treated with pregnancy-related factors were investigated. The fetal antigen rejection-based CBA/J $\times$ DBA/2J mouse model (poor outcome pregnant mice; POPM) was used to characterize ILC antigen presentation potential in normal and immunologically disturbed pregnancies. ILC antigen presentation potential was characterized by flow cytometry and qPCR. We discovered that the distribution of ILC subsets changed during both human and murine pregnancy. Moreover, the pregnancy was accompanied by reduced $\mathrm{MHCII}$ expression in splenic ILCs during normal pregnancy $(C B A / J \times B A L B / c$; good outcome pregnant mice; GOPM) but increased in splenic and intestinal ILCs of CBA/J $\times$ DBA/2J mice. In vitro, splenic ILCs from pregnant mice increased MHCII expression after stimulation with IL-1ß and IL-23. In contrast, uterine ILCs displayed lower MHCII expression, which remained unchanged after stimulation. Finally, pregnancy-related factors and hormones present in the uterine environment reduced antigen presentation potential of human ILCs in vitro. Together, these data indicate that, during pregnancy, peripheral and especially uterine ILCs adapt their antigen presenting potential to maintain a level of tolerance and support pregnancy. Reproduction (2020) $\mathbf{1 6 0} 155-169$
\end{abstract}

\section{Introduction}

From an immunological perspective, pregnancy is characterized by an initial pro-inflammatory implantation phase followed by an anti-inflammatory switch that prevails until the onset of labor (Mor et al. 2017). The fine-tuned changes in the immunological dominant tone (Aghaeepour et al. 2017) are associated with the actions of hormones and pregnancy-associated molecules on immune cells including lymphocytes at the fetomaternal interface (Muzzio et al. 2014a, Napso et al. 2018). During different stages of gestation, a variety of immune cells and mediators must ensure a proper defense against pathogens and allow the semiallogeneic fetus to grow under tolerogenic conditions simultaneously (Bartmann et al. 2014, Solders et al. 2017, Li et al. 2018, Vazquez et al. 2018, Slutsky et al. 2019). Infectious agents alter this balance and represent a risk for both the fetus and the mother (Mor et al. 2011). However, inflammatory conditions, even in the absence of infections, may represent a risk for pregnancy outcome (Romero et al. 2007). Recent reports indicate that the presence of commensal bacteria (excluding infections) at the fetomaternal interface does not necessarily alter pregnancy outcome (Steel et al. 2005, Satokari et al. 2009, Doyle et al. 2014). Since underlying tolerance mechanisms are not completely understood, further research is necessary to determine those causes and further prevent such conditions.

The $\mathrm{CBA} / \mathrm{J} \times \mathrm{DBA} / 2 \mathrm{~J}$ mouse model has been useful in the past to characterize immune components that take part in pro-inflammatory pregnancy disturbances (Clark et al. 1980, Bonney \& Brown 2014). Furthermore, $\mathrm{CBA} / \mathrm{J} \times \mathrm{DBA} / 2 \mathrm{~J}$ pregnancies share several components with human intrauterine growth restriction (IUGR), such as inadequate arterial remodeling at the implantation site, complement deposition on trophoblasts, neutrophil and monocyte infiltration and dysregulation of cytokine expression (Dixon et al. 2006, Girardi et al. 2006, Scifres \& Nelson 2009, Whitley \& Cartwright 2009, McKelvey et al. 2016). In this model, contrary to the physiological tolerance induction, the maternal immune system reacts against fetal antigens by excessive proinflammatory responses that lead to fetal resorption and IUGR (Ahmed et al. 2010, Clark et al. 2013). These conditions can be reverted by administration 
of anti-inflammatory agents or by interfering antigen presentation through blocking of accessory molecules CD80/CD86 (Chaouat et al. 1995, Jin et al. 2005). Furthermore, this model highlighted the importance of non-infectious factors, such as the gut microbiome, on priming immune reactions and possibly leading to pregnancy complications (Hamilton \& Hamilton 1987, Clark et al. 2004). Together, this mouse model represents a tool to study the pathology of inappropriate tolerance induction during pregnancy.

Recent reports point to innate lymphoid cells (ILCs) as a significant player in physiological and pathological processes during pregnancy (Male et al. 2010, Doisne et al. 2015, Vacca et al. 2015, Croxatto et al. 2016, Xu et al. 2018). Despite their low numbers, ILCs play strategic roles linking native and adaptive immune responses in different organs (Withers 2016). In terms of cytokine production, ILCs resemble T helper cells (Diefenbach et al. 2017). Therefore, they can be subdivided into three major groups: ILC1 (similar to Th1 T cells), ILC2 (similar to Th2 T cells) and the LTi/ILC3 group (similar to Th17 T cells) (Colonna 2018).

Apart from their cytokine secretory capacity, ILCs can shape adaptive immune responses by direct cellcell contact. In this sense, they influence the production of antibodies by interacting with marginal zone B cells and plasma cells in the spleen (Magri et al. 2014). This interaction is mediated by the expression of the B-cell activating factor of the TNF family (BAFF), the ligand of CD40 (CD40L), the NOTCH2 ligand Delta-like 1 (DLL1) and a proliferation-inducing ligand (APRIL, in mice). Marginal zone B cells and immunoglobulin expression are modified during murine pregnancy. These changes are thought to reflect adaptations of the immune system to prioritize fast antibody production during Th2dominant phases of pregnancy (Muzzio et al. 2014b, 2016). It is still unclear whether cells that influence $B$ cell function, as T-helper cells or ILCs, are involved in this phenomenon.

Increasing evidence has highlighted the importance of ILCs as antigen presenting cells (Hepworth et al. 2013, Oliphant et al. 2014, von Burg et al. 2014, 2015, Robinette \& Colonna 2016). ILC2s and ILC3s can process and present antigens in association with the major histocompatibility complex class II (MHCII) molecules (Robinette \& Colonna 2016). Through the accompanying expression of accessory molecules such as CD40, CD80 and CD86, ILCs prime CD4+ T-cell responses (von Burg et al. 2015). On the other hand, in the absence of costimulatory molecules, the antigen presentation leads to active tolerance, inhibiting $\mathrm{CD} 4^{+}$ T-cell response. As a consequence, the pro-inflammatory Th1/Th17 response is inhibited and regulatory T-cell development is promoted. This is a crucial element for microbiological tolerance against commensal bacteria in the gut (Hepworth et al. 2013).
As the T-cell response to the fetal antigens is regulated by maternal APCs rather than by the direct recognition on fetal cells, we focused on maternal changes in ILCs (Erlebacher et al. 2007). The aim of this work is to characterize ILC potential to interact with the adaptive immune system in terms of expression of antigen presentation markers during pregnancy.

\section{Materials and methods}

\section{Human samples}

Venous blood was collected from healthy pregnant women in the first or third trimester during routine controls by the medical staff of the Clinic of Obstetrics and Gynecology. Blood from non-pregnant women was obtained during blood donation. The absence of infections was checked by medical staff as part of the routine. Only women in reproductive age were included in the study. Volunteers were informed and gave their written consent. The study was approved by the Ethics Committee of the University Medicine Greifswald (BB 126/13a and BB 136/16). Peripheral blood was centrifuged at $1300 \mathrm{~g}$ and room temperature for $10 \mathrm{~min}$ to discard the serum. The cellular components were mixed with an equivalent volume of DPBS (PAN-Biotech GmbH, Aidenbach, Germany) and layered on Lymphoprep ${ }^{\text {TM }}$ (STEMCELL Technologies Inc., Vancouver, Canada). PBMCs were isolated following manufacturer's instructions. Subsequently, $\mathrm{CD}^{+}$cells were depleted using EasySep ${ }^{\text {TM }}$ Human CD3 Positive Selection Kit II (STEMCELL Technologies Inc., Vancouver, Canada) to improve analysis resolution and avoid T-cell contamination.

Decidual lymphocytes were obtained from decidua basalis and parietalis of primary caesarean section at term using a modified published protocol (Xu et al. 2015). Cotyledons with decidua basalis and the outer layer of the amniotic membrane of decidua parietalis were scraped off and transferred into C tubes (Miltenyi Biotec, Bergisch Gladbach, Germany). gentleMACS (Miltenyi Biotec, Bergisch Gladbach, Germany) was used for tissue disintegration with collagenase and DNAse applying the program ' $m$ _heart_02'. Subsequently, it was incubated at $37^{\circ} \mathrm{C}$ for $60 \mathrm{~min}$ and inverted every 15 min. Afterwards, the cell suspension was filtered through a pre-moistened cell strainer. Cells were centrifuged at $350 \mathrm{~g}$ for $10 \mathrm{~min}$. The cell suspension was layered on Lymphoprep ${ }^{\mathrm{TM}}$ to separate mononuclear cells. The removed placenta with the clamped umbilical cord was used to take the umbilical cord blood sample. Blood vessels at the fetal side were cannulated and blood aspirated. Mononuclear cells were isolated as described. Umbilical cord blood stem cells were separated by positive selection, applying CD34 MicroBead Kit UltraPure (Miltenyi, Bergisch Gladbach, Germany) according to manufacturer's instructions.

\section{Animals}

Female $\mathrm{CBA} / \mathrm{J}\left(\mathrm{H} 2^{\mathrm{k}}\right)$ and male $\mathrm{DBA} / 2 \mathrm{~J}\left(\mathrm{H} 2^{\mathrm{d}}\right)$ mice were purchased from Charles River or Janvier Labs (Saint-Berthevin Cedex, France). $\mathrm{C} 57 \mathrm{Bl} / 6$ females and BALB/C $\left(\mathrm{H} 2^{\mathrm{d}}\right)$ males were 
bred in the Central Service and Research Facility for Animals (ZSFV) of the University of Greifswald. The mice were kept co-housed in a $12 \mathrm{~h}$ light:12 h darkness cycle with food and water supply ad libitum. CBA/J females mated with DBA/2J served as a mouse model for immune-induced pathological pregnancies (Clark et al. 1986, Raghupathy 1997) which are, therefore, named as 'poor outcome pregnancy' mice (POPM). $\mathrm{CBA} / \mathrm{J}$ females mated with BALB/C males served as 'good outcome pregnancy' mice (GOPM). Non-pregnant females served as further control (non-pregnant mice; NPM). For other experiments, $\mathrm{C} 57 \mathrm{Bl} / 6$ females were mated with BALB/C males to ensure semi-allogeneic fetuses. Mated mice were checked for vaginal plug every morning. The observation of a plug was declared day 0 of pregnancy. Subsequently the doe was separated from the male. After killing, peritoneal cavity lavage, thymus, uterus, spleen or Payer's patches were obtained accordingly.

Thymus, spleen and Payer's patches were mashed through a $40 \mu \mathrm{m}$ EASYstrainer ${ }^{\mathrm{TM}}$ (greiner bio-one, Kremsmünster, Austria) and washed with DPBS $+10 \%$ FBS (PAN-Biotech $\mathrm{GmbH}$, Aidenbach, Germany) twice to obtain single cell suspensions. The uterus was mechanically disrupted by a scissor, while DNase I (10 mg/mL in HBSS) was added to avoid DNA sticking cells together. To digest the tissue, $0.5 \%$ collagenase (in DPBS) was added and incubated for at least $1 \mathrm{~h}$ at $37^{\circ} \mathrm{C}$. Single cells were separated by sieving the suspension through a cell strainer.

\section{Cell culture}

Umbilical cord blood CD34+ ${ }^{+}$stem cells were cultured in ILC3 differentiation medium (10\% FBS, 1\% Penicillin-Streptomycin (PAN-Biotech $\mathrm{GmbH}$, Aidenbach, Germany), $20 \mathrm{ng} / \mathrm{mL} \mathrm{SCF}$, $20 \mathrm{ng} / \mathrm{mL}$ IL-7, $20 \mathrm{ng} / \mathrm{mL} \mathrm{IL-15}$ and $10 \mathrm{ng} / \mathrm{mL}$ Flt-3 ligand (Miltenyi, Bergisch Gladbach, Germany) in RPMI 1640 (PAN-Biotech $\mathrm{GmbH}$, Aidenbach, Germany)) (Moretta et al. 2016). In addition to the extensive analysis performed by Moretta et al., we confirmed the expression of ILC3-specific markers and cytokines after activation (Supplementary Fig. 1C, see section on supplementary materials given at the end of this article).

Recombinant human TGF- $\beta 1$ (20 ng/mL; R\&D, Minneapolis, MN, USA), hCG (20 or $200 \mathrm{IU} / \mathrm{mL}$; Ovitrelle ${ }^{\circledR}$, Merck), recombinant human VEGF-121 (20 ng/mL; Biomol, Hamburg, Germany), recombinant human progesterone (30 or $300 \mathrm{ng} /$ $\mathrm{mL}$ ) or estradiol (3 or $20 \mathrm{ng} / \mathrm{mL}$; Sigma-Aldrich) were added accordingly. For mRNA analyses, cells were pre-treated with $1 \mu \mathrm{M}$ 5-Aza-2'-deoxycytidine (Aza) for $48 \mathrm{~h}$ and compared to non-treated controls. Thereafter, CD3-CD19-CD20-CD94NKp44+ ILC3s were sorted and incubated with hCG or TGF- $\beta 1$ as described previously at 170,000-200,000 cells per well. Murine cells were cultured in hormone-depleted basic medium $(10 \%$ hormone-depleted FBS by activated carbon adsorption, 1\% Penicillin-Streptomycin and $55 \mu \mathrm{M}$ $\beta$-mercaptoethanol (Sigma-Aldrich) in RPMI 1640). Murine ILC3 were subsequently activated by the addition of $20 \mathrm{ng} / \mathrm{mL}$ IL-1 $\beta$ and $20 \mathrm{ng} / \mathrm{mL}$ IL-23 (both from BioLegend, San Diego, CA, USA) and incubated for $48 \mathrm{~h}$.

\section{Flow cytometry}

Single cell suspensions were obtained as previously described (Packhäuser et al. 2017). Preincubation with Fixable Viability Dye (Thermo Fisher Scientific Inc.) was performed for $30 \mathrm{~min}$ at $4{ }^{\circ} \mathrm{C}$. Murine cells were pre-incubated with CD16/32 mAb Fc block (BD Pharmingen, Heidelberg, Germany) for 5 min. Extracellular antigens were stained with fluorochrome-labeled antibodies for $30 \mathrm{~min}$ at $4^{\circ} \mathrm{C}$. Fixation and permeabilization of the cells were accomplished with either Foxp3 staining buffer set (Thermo Fisher Scientific Inc.) when transcription factors were stained or otherwise with BD Perm/Wash and BD Cytofix/Cytoperm (BD Biosciences, Franklin Lakes, NJ, USA) according to manufacturer's instructions. Subsequently, cells were incubated with fluorochrome-labeled antibodies for 30 min at $4^{\circ} \mathrm{C}$ for intracellular staining. For every wash step and for measurement, FACS buffer was used (1\% BSA (Sigma-Aldrich), $0.1 \% \mathrm{NaN}_{3}$ (Carl Roth, Karlsruhe, Germany) in DPBS). Data were acquired with FACSCanto (BD Biosciences, Franklin Lakes, NJ, USA). At least 5 million cells of CD3-depleted human maternal PBMCs were measured. FMO (fluorescence minus one) controls were performed. Data were analyzed using Flow) ${ }^{\text {TM }} 10.4$ software (Flowjo, LLC, Ashland, TN, USA). Percentages as well as the absolute mean fluorescence intensity of the stained samples (MFI) were analyzed.

Antibodies used for flow cytometry staining $\left(' h^{\prime}=\right.$ antihuman, ' $\mathrm{m}$ ' =anti-murine; clone name given in brackets): h-TCR $\gamma / \delta$ (B1), h-CD11c (B-ly6), h-CD117 (YB5.B8), h-CD127 (HIL-7R-M21), h-CRTH2 (BM16), h-CD1a (HI149), h-lin3 (CD3: SK7/Leu-4, CD14: M९P9, CD19: SJ25C1, CD20: L27), h-CD123 (7G3), h-CD94 (HP-3D9), h-NKp44 (p44-8), h-CD40 (5C3), h-CD69 (FN50), h-CD80 (L307.4), h-CD56 (B159), m-CD3e (145-2C11), m-CD8a (53-6.7), m-CD11b (M1/70), $\mathrm{m}-\mathrm{CD} 80$ (16-10A1) and m-CD117 (YB5.B8) were obtained from BD Biosciences (Franklin Lakes, NJ, USA). m-Ter119 (TER-119), m-CD127 (eBioSB/199), m-CD117 (29A1.4), m-T1/ST2 (RMST2-2), m-CD40L (MR1) and m-ROR $\gamma$ t (B2D) were ordered from Thermo Fisher Scientific Inc. h-CD34 (561), h-TCR $\alpha / \beta$ (IP26), h-CD303 (201A), h-FceRl $\alpha$ (AER-37; CRA-1), m-CD4 (RM4-5), m-CD19 (6D5) and m-DLL1 (HMD1-3) were from BioLegend (San Diego, CA, USA). h-/m-BAFF (Buffy 2) was ordered from Abcam. m-MHCII (REA528) was obtained from Miltenyi, Bergisch Gladbach, Germany.

\section{Cell sorting and functional characterization}

In vitro differentiated ILC3s were sorted as CD3-CD19-CD20CD94-NKp44+ using a BD FACS Aria III cell sorter (purity $>95 \%$ ). To verify the presence of $\mathrm{NCR}^{+}$ILC3s, sorted cells were stained with specific antibodies either directly after sorting or after $5 \mathrm{~h}$ stimulation with PMA and ionomycin in the presence of brefeldin A. After sorting, the cells displayed a CD3-CD14CD19-CD20-CD94-NKp44+CD56+ROR $\gamma \mathrm{t}^{+}$phenotype and expressed CD69, HLA-DR, IL-8 and IL-22 after stimulation (Fig. 5A). The presence of RORyt, HLA-DR, CD69, IL-8 and IL-22 mRNA was also detected by qPCR. Additionally, IL-8 was detected in the supernatants of sorted cells by ELISA (data not shown). 


\section{Real-time PCR}

After treatment, RNA from sorted NKp44+ILC3s was isolated using TriFast $^{\text {TM }}$ peqGOLD (VWR, Radnor, PA, USA). RNA concentration was spectrophotometrically assessed in the NanoPhotometer PEARL (IMPLEN, Munich, Germany). RNA was reverse transcribed by applying High Capacity cDNA Archive Kit (Applied Biosystems). For the qPCR, the samples were amplified in duplicate and nontemplate controls were included. Primer pairs were chosen to span an exon-exon junction, avoiding genomic DNA amplification. Real-time PCR was performed using Power

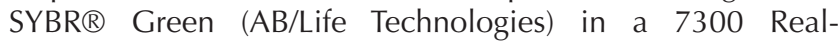
time PCR System (Applied Biosystems) with $\beta$-actin as housekeeping gene. Primer sequences were the following: HLA-DRA forward: ACTATACTCCGATCACCAATGTACCTC; HLA-DRA reverse: AAGACTGTCTCTGACACTCCTGTGG; CD40 forward: ACCCTTGGACAAGCTGTGAGAC; CD40 reverse: TTTGATAAAGACCAGCACCAAGAG; CD80 forward: GGGCACATACGAGTGTGTTGTT; CD80 reverse: TCAGCTTTGACTGATAACGTCACTTC and ACTB forward: CCTGGCACCCAGCACAAT; ACTB reverse: GCCGAT CCACACGGAGTACT.

\section{Statistical analysis}

In vivo mouse data and human peripheral blood data were analyzed by one-way ANOVA, followed by a Tukey-Kramer post-test. Data concerning the effect of pro-inflammatory cytokines on murine ILCs were analyzed by paired $t$-test. Hormonal treatment data were analyzed by ANOVA for multiple measurements with Dunnett's post test against nontreated controls (hCG, estradiol and progesterone treatments) or paired $t$-test (TGF- $\beta 1$ and VEGF). Graphs show mean \pm S.E.M., and results mention mean and 95\% confidence intervals. GraphPad PRISMC 5.01 was used for statistical analyses. Analyses were performed according to statistical advises of the Institute of Bioinformatics of the University of Greifswald.

\section{Results \\ Murine ILCs distribution is altered in pro-inflammatory pregnancies}

To provide an initial impression of ILC distribution during normal and disturbed murine pregnancies, we chose a strategy to differentiate four main subsets of $\mathrm{Lin}^{-} \mathrm{CD} 127^{+}$ ILCs, including CD117- ILCs, CD117+NKp46-ST2+ ILCs, CD $117^{+} \mathrm{NKp} 46^{-\mathrm{ST}} 2^{-}$ILCs and CD $117^{+} \mathrm{NKp} 46^{+}$ILCs (Fig. 1A). This strategy allowed us to estimate the distribution of ILC1s, ILC2s, NCR-ILC3s and NCR+ILC3s, respectively. Consistent with the Th1 suppression observed in pregnancy (Sykes et al. 2012), the proportions of ILC1s were reduced in spleens from GOPM as compared to NPM $(0.142(0.117,0.168) \%$ vs $0.197(0.171,0.223)$ $\%)$. The proportion of the NCR subset of ILC3s was found increased in POPM in peritoneal cavity lavage (PerC) $(0.0223(0.0176,0.0270) \%$ vs 0.0133 (0.0100, $0.0166) \%$. We found increased ILC2 proportions in
Payer's patches (PP) $(0.0351 \quad(0.0236,0.0467) \%$ vs $0.0227(0.0179,0.0275) \%)$ and PerC of POPM $(0.0466$ $(0.0318,0.0630) \%$ vs $0.025(0.0195,0.0305) \%)$.

In uterus, we found higher percentages of ILCs during pregnancy. However, no differences were found between both groups of pregnant mice.

Applying a similar approach commonly used to detect human circulating ILCs (Munneke et al. 2014, Xiong \& Turner 2018, Loyon et al. 2019), we studied the distribution of blood-derived ILC subsets during human pregnancy (Fig. 1B). We found no differences in ILC1 and ILC2 proportions between pregnant and non-pregnant controls. In contrast, we observed reduced NCR-ILC3s at the third trimester of pregnancy $(1.076(0.000,2.16)$ $\%$ vs $8.358(6.21,10.5) \%$ ) and increased NCR $^{+}$ILC3s at $^{2}$ the first trimester of pregnancy $(0.557(0.127,0.988) \%$ vs $0.174(0.0920,0.256) \%)$.

\section{Antigen presentation potential is reduced in murine peripheral ILCs of spleen and Peyer's patches during healthy pregnancy}

Both ILC subsets increased in POPM (ILC2s and ILC3s), can express $\mathrm{MHCll}$ and act as antigen presenting cells (Oliphant et al. 2014, von Burg et al. 2014). Therefore, we studied the expression of antigen presentationrelated molecules $\mathrm{MHCII}$ and CD80 in the CBA mouse model (Fig. 2A). We found significant differences in the expression levels of $\mathrm{MHCll}$ as well as in the percentage of $\mathrm{MHClI}^{+} \mathrm{ILC} 2 \mathrm{~s}$ and $\mathrm{MHCl}+\mathrm{ILC}^{+} \mathrm{s}$. The expression of $\mathrm{MHCII}$ was significantly reduced in splenic ILC2s of both pregnant mice, but it was higher in POPM than in GOPM (relative expression: $1(0.906,1.09)$ vs 0.309 $(0.0800,0.539)$ vs $0.620(0.447,0.792)$ for NPM, POPM and GOPM, respectively). ILC3s from POPM showed higher expression of $\mathrm{MHCll}$ than NPM in PP (relative expression: $1.48(1.15,1.82)$ in POPM vs $1(0.773,1.23)$ in NPM). In POPM, higher percentages of $\mathrm{MHClI}^{+}$were found among splenic ILC3s (48.1\% (37.6\%, 58.6\%)) compared to GOPM $(27.4 \%(15.2 \%, 39.5 \%))$. Also ILC3s from PP were increased $(21.0 \%(18.6 \%, 23.3 \%)$ as compared to NPM $(17.6 \%(16.0 \%, 19.2 \%))$ and GOPM $(17.1 \%(15.7 \%, 18.4 \%))$. We found no differences in the expression of the costimulatory molecule CD80.

We also found that CD40L was significantly higher expressed in ILCs from POPM $(96.6(75.5,118) \mathrm{MFI})$ compared to ILCs from normal pregnant mice (47.9 (15.0, 80.9) MFI) (Fig. 2B). The proportion of DLL1+ILCs was higher in both groups of pregnant mice compared to NPM $(5.24(3.43,7.04) \%$ in GOPM, $4.65(4.09,5.22)$ $\%$ in POPM, vs $2.54(1.79,3.29) \%$ in NPM).

\section{Antigen presentation potential is reduced in murine uterine ILCs}

The changes observed in the CBA mouse model suggested that healthy pregnancies are associated 

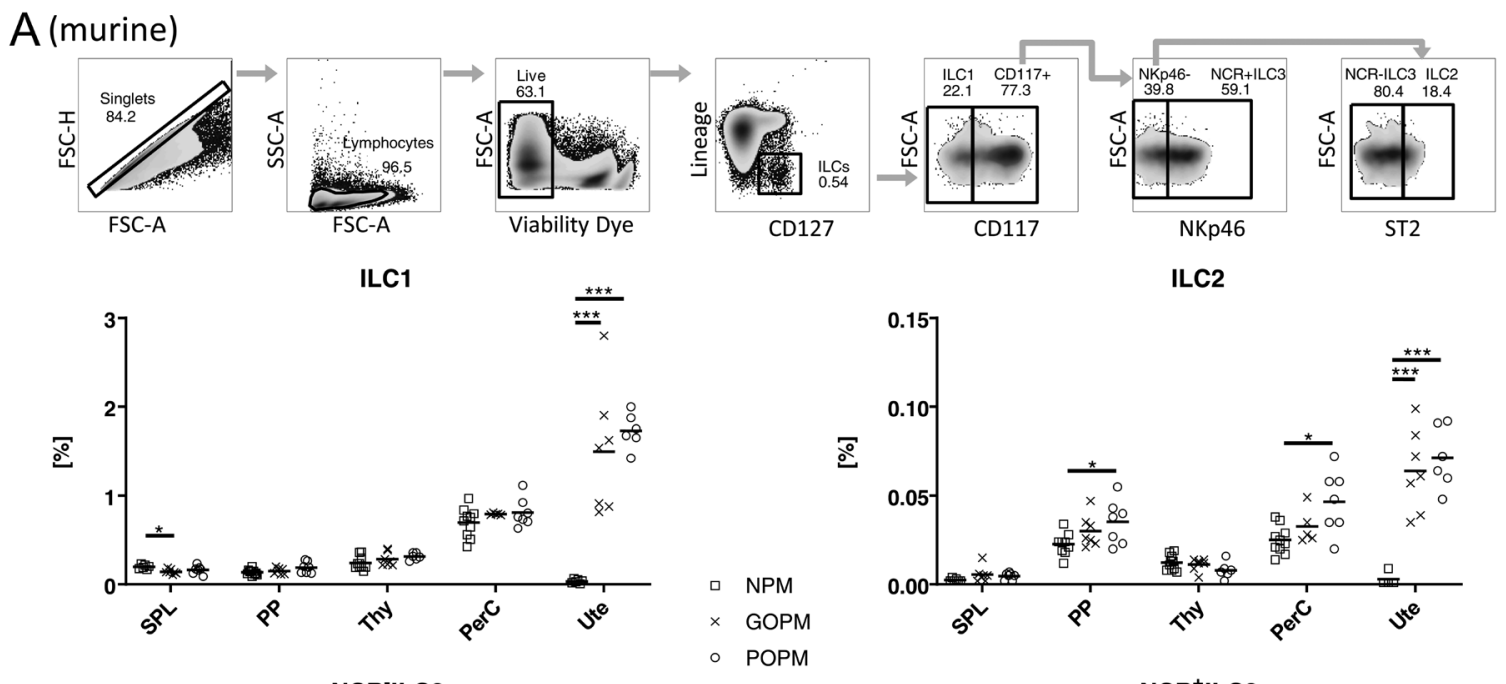

NCR'ILC3
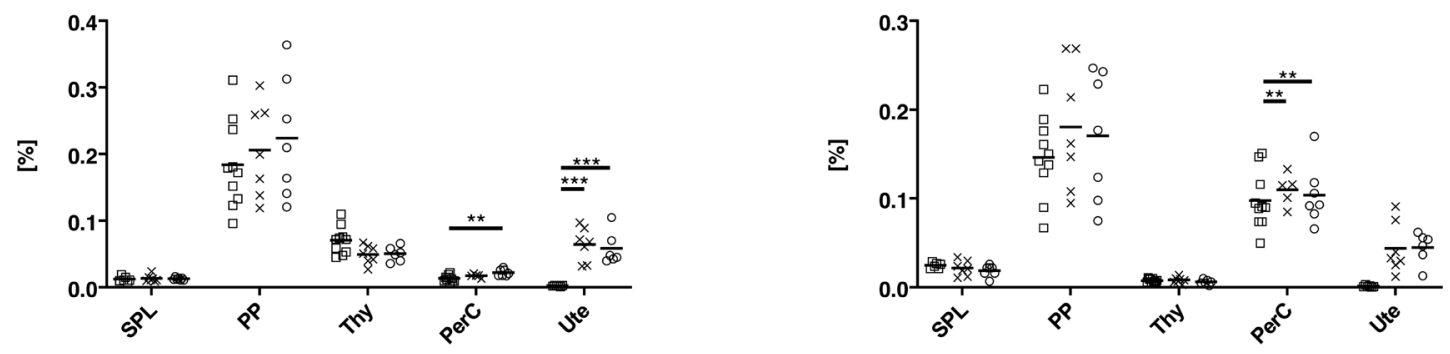

\section{$B$ (human)}

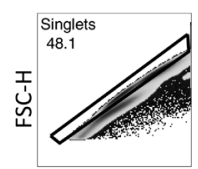

FSC-A
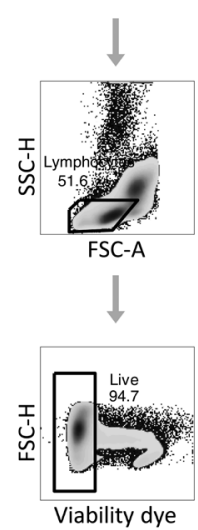
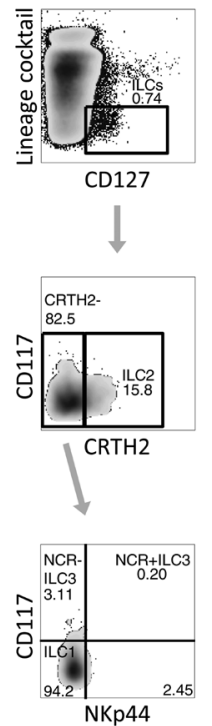

ILC 1

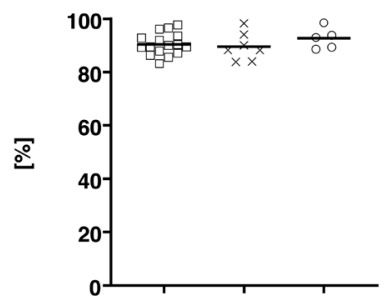

ILC 2

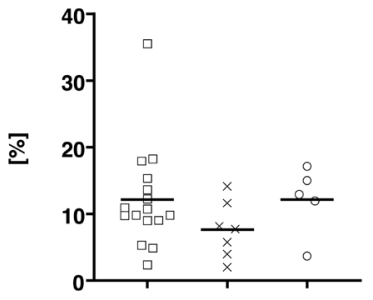

NCR- ILC3

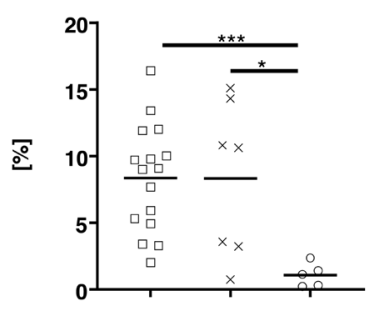

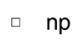

$\times 1$ st

3rd

NCR+ ILC3

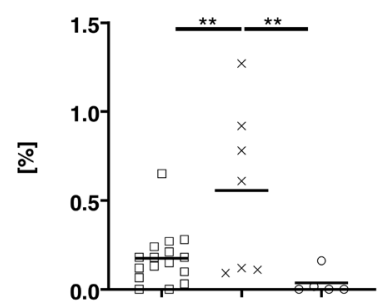

Figure 1 Pregnancy affects ILC subset distribution in mice and human. Percentages of ILC subsets were determined in (A) murine organs and (B) maternal peripheral blood by flow cytometry analysis. (A) Spleen (SPL), Peyer's patches (PP), thymus (Thy), peritoneal cavity lavage (PerC) and uterus (Ute) of non-pregnant mice (NPM), 'good outcome pregnancy' mice (GOPM; $14 \mathrm{dpp}$ ) and 'poor outcome pregnancy' mice (POPM; 14

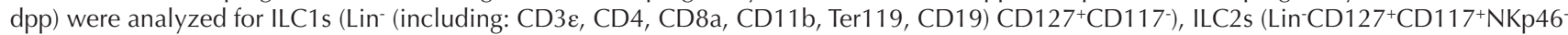

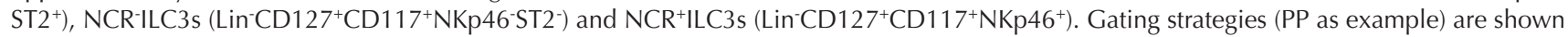
at the top. (B) The distribution of ILC1s (Lin- (including: CD1a, CD11C, CD20, CD19, CD3, CD123, TCR $\gamma / \delta, C D 94, C D 34, T C R \alpha / \beta, C D 303$,

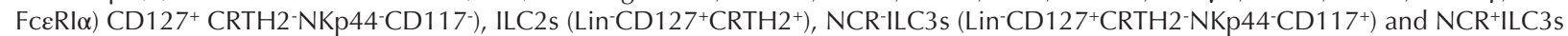
$\left(\mathrm{Lin}-\mathrm{CD} 127^{+} \mathrm{CRTH} 2{ }^{-} \mathrm{NKp} 44^{+} \mathrm{CD} 117^{+}\right)$in peripheral blood of non-pregnant (np) and pregnant women of the first or third trimester was determined. Plots on the left show the gating strategy. Data are shown with mean and were analyzed by one-way ANOVA, followed by a Tukey-Kramer post-test. ${ }^{*} P<0.05,{ }^{* *} P<0.01,{ }^{* * *} P<0.001$. The number of biological replicates for murine experiments (NPM/GOPM/POPM) were: SPL, 6/7/7; PP 10/7/7; Thy, 10/7/6; PerC, 10/5/7; Ute, 6/6/6. The number of human samples were (np/first/third) 16/7/5. 
A (murine)

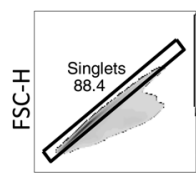

FSC-A

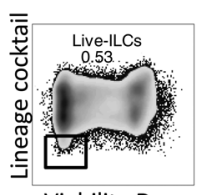

Viability Dye
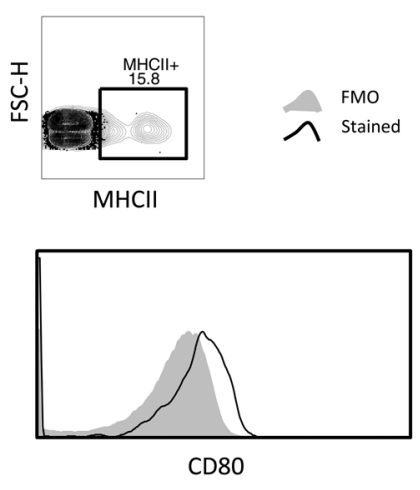

ळ
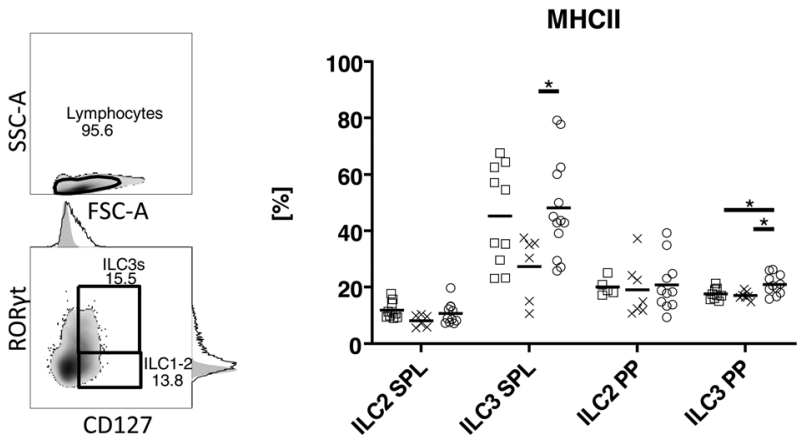

CD80

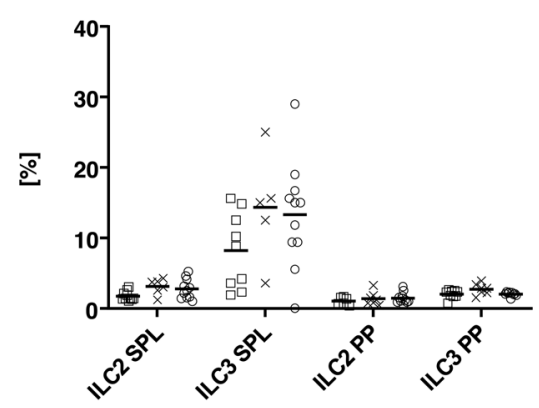

MHCII

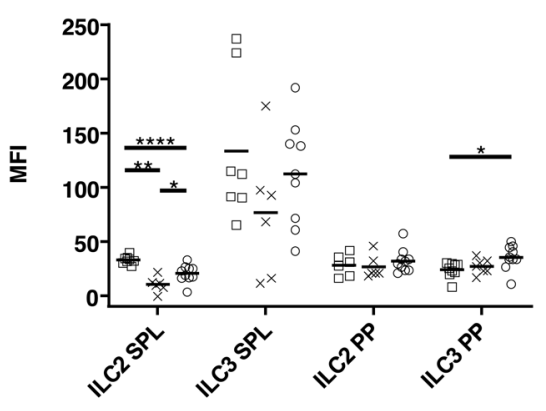

CD80

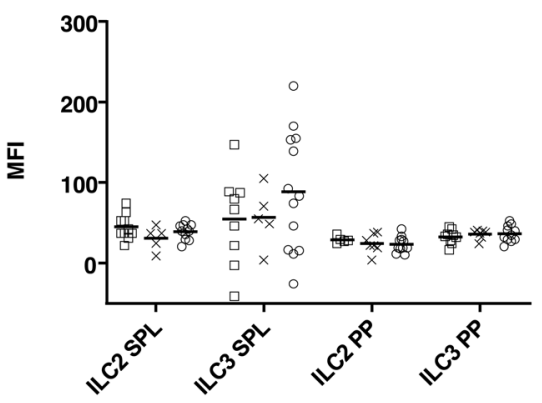

\section{$\mathrm{B}$ (murine)}

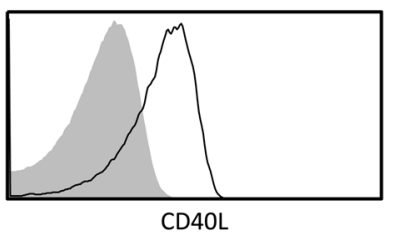

FMO

Stained

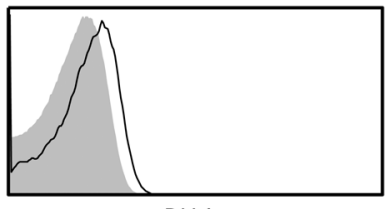

DLL1
CD40L

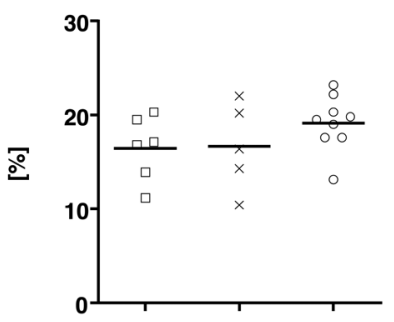

DLL1

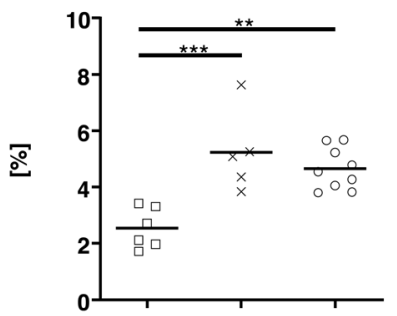

CD40L

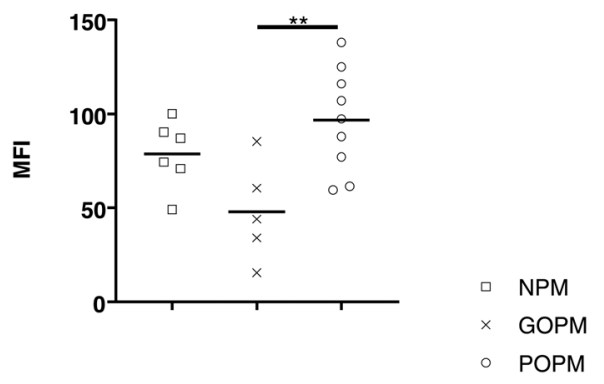

DLL1

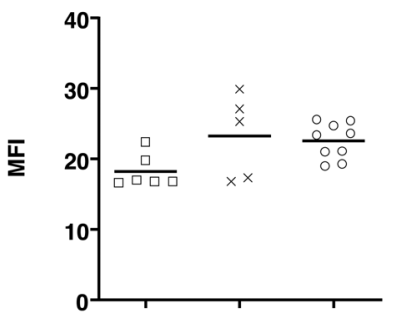

Figure 2 Normal murine pregnancies are associated with a reduction of the antigen presentation potential of ILCs. Extracellular molecules important for (A) antigen presentation, costimulation and (B) cell contact-dependent communication were analyzed by flow cytometry. (A) Expression of major histocompatibility complex class II (MHCII) and costimulatory molecule CD80 were determined on Lin (including: CD3 $\varepsilon_{\text {, }}$

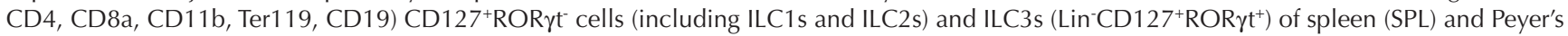
patches (PP) from non-pregnant mice (NPM), 'good outcome pregnancy' mice (GOPM; $14 \mathrm{dpp}$ ) and 'poor outcome pregnancy' mice (POPM; 14 dpp). (B) The expression of CD40 ligand (CD40L) and Delta-like protein 1 (DLL1) were examined on splenic ILC3s (CD38 ${ }^{-} \mathrm{CD} 19-\mathrm{ROR}^{+} \mathrm{t}^{+}$) from NPM, GOPM and POPM. Plots on the left (A) show gating strategy (PP as example). Histograms (A and B) represent expression analysis with the FMO as grey area and the stained sample as line. Data are shown with mean and were analyzed by one-way ANOVA, followed by a TukeyKramer post-test. ${ }^{*} P<0.05,{ }^{* *} P<0.01,{ }^{* * *} P<0.001,{ }^{* * *} P<0.0001$. The number of biologicals replicates in (A) (NOM/GOPM/POPM) was $6 / 7 / 11$ and in (B) was 6/5/9. 
with a systemic reduction of $\mathrm{MHCll}$ expression on ILCs. Soluble mediators known to influence immune function systemically during pregnancy are present at high concentrations in the uterus. These and other local factors (decidual stromal cells, trophoblasts, oxygen availability) are thought to determine a distinct uterine phenotype of some ILCs as the uterine NK cells. We moved forward to evaluate whether uterine ILCs antigen presentation potential differed from peripheral counterparts.

Organ-specific function involving antigen presentation has been already observed in ILC3s. For instance, ILC3 antigen presentation was shown to promote immune responses in organs like spleen but to induce tolerance to commensal bacteria in the gut (von Burg et al. 2014). To evaluate the antigen presentation potential of uterine ILC3s, we compared splenic and uterine ILC3 responses to inflammatory stimuli. We observed that splenic, but not uterine ILC3s, upregulated MHCII expression upon stimulation (from $338(196,481) \mathrm{MFI}$ on controls to 1986 (174, 1998) MFI after stimulation) (Fig. 3A and B). MHCll expression levels remained low in uterine ILC3s, in contrast to splenic ILC3s $(36.0(19.0,53.0 \mathrm{MFI}$ on controls, 38.5 (28.6, 48.4) MFI after stimulation). Stimulation also induced the expression of $\mathrm{MHCl}^{+} \mathrm{ILCs}$ in spleen $(42.9(36.6,49.1) \%$ to $55.4(39.8,70.9) \%$ after stimulation) and uterus $(6.99(0.66,13.3) \%$ to 9.32 $(2.19,16.4) \%$ after stimulation). We found no significant increase of CD80 expression in ILC3s, while CD40 was increased in splenic ILC3s (relative MFI: $1(0.108,1.89)$ to $1.30(0.486,2.11))$ and reduced in uterine ILC3s (relative MFI: $1(0.709,1.29)$ to $0.961(0.660,1.26)$ ). The percentage of activated CD69+ILC3s was increased in both cases (from $8.04(1.30,14.8)$ to $15.1(7.31,22.8)$ $\%$ in splenic ILC3s and from $23.3(13.2,33.4)$ to 35.5 $(21.8,49.1) \%$ in uterine ILC3s)

\section{Human uterine ILCs include $\mathrm{MHCII}^{+}$cells}

Mouse data suggested that uterine ILC3s may differ substantially from their peripheral counterparts in terms of antigen presentation potential. We wondered whether human ILC3s would display similar characteristics.

Therefore, the expression of the antigen presentation marker MHCII and the co-stimulating molecule CD80 was assessed on decidual basalis and decidua parietalis ILC3s after primary cesarean section at term. ILCs were present at higher percentages in decidua parietalis than in decidua basalis $(0.40(0.20,0.60) \%$ vs $0.17(0.05,0.28)$ $\%)$, while no significant differences in the percentage of ILC3s were observed (Fig. 4A and B). The expression of $\mathrm{MHCll}$ was detected in only 5.74 (minimum 1.10 , maximum 15.81) \% of decidua basalis ILC3s and 2.77 (minimum 1.10, maximum 5.17) \% of decidua parietalis ILC3s, but the level of expression of MHCII did not differ significantly between both. The expression of CD80, however, was higher in decidua basalis ILC3s than in decidua parietalis ILC3s $(148.0(102.8,193.2)$ vs 102.6 (59.67, 145.5) MFI).

\section{Pregnancy-related hormones reduce ILC antigen presentation potential in vitro}

Since antigen presentation potential is low in murine and human uterine ILC3s, we studied the role of pregnancyrelated hormones on antigen presentation molecules. TGF- $\beta 1$ treatment caused a significant reduction in the expression of HLA-DR (relative MFI: $1(0.603,1.40)$ to $0.420(0.252,0.588))$ and the costimulatory molecule CD80 (relative MFI: $1(0.620,1.379)$ to 0.621 (0.295, 0.948)) (Fig. 5A and B). Also the expression of CD69 was reduced after TGF- $\beta 1$ treatment (relative MFI: 1 $(0.812,1.19)$ to $0.907(0.745,1.07))$. No effect on CD40 expression could be seen. TGF- $\beta 1$ treatment also reduced HLA-DR mRNA levels after treatment with Aza.

HCG, an important early pregnancy regulator, suppressed HLA-DR expression in ILC3s (relative MFI: $1(0.602,1.40)$ to $0.840(0.506,1.17))$. In contrast, hCG treatment upregulated CD40 (relative MFI: 1 (0.471, $1.53)$ to $1.13(0.541,1.72)$ ) and CD80 (relative MFI: 1 $(0.620,1.38)$ to $1.08(0.682,1.49))$ expression without affecting CD69 expression pattern. A hCG-dependent upregulation of CD40 at mRNA level could as well be observed after treatment with Aza (Fig. 5C).

No effect of VEGF, progesterone or estradiol on the expression of HLA-DR, CD40, CD80 or CD69 could be demonstrated (Fig. 5A and B).

\section{Discussion}

Recent studies reported the presence of a microbiome in healthy term placentae (Steel et al. 2005, Stout et al. 2013, Aagaard et al. 2014, Doyle et al. 2014). The presence of bacteria in healthy pregnancies represents a major challenge for the maternal immune system homeostasis and current models of immune response to pregnancy, as defense mechanisms must be balanced with fetal and, at the same time, microbiome tolerance. Classically confined as pro-inflammatory cells and owning antigen presentation potential, ILC3s would harmonize in a microbiome-positive model of pregnancy only if strongly regulated. We observed that uterine ILCs behave refractory to the stimulation with pro-inflammatory cytokines, different than splenic ILCs. Moreover, pregnancy-related hormones reduced their antigen presentation potential in vitro.

ILCs affect tissue remodeling and immune regulation in several tissues. Their role at the fetomaternal interface and in reproduction remains unclear. Murine experiments indicate that they might play a physiological role in early phases of pregnancy (Doisne et al. 2015, Vacca et al. 2015, Croxatto et al. 2016, Bartemes et al. 2018). Recent studies indicated an association between their expression pattern and cytokine secretion with 


\section{A (murine)}
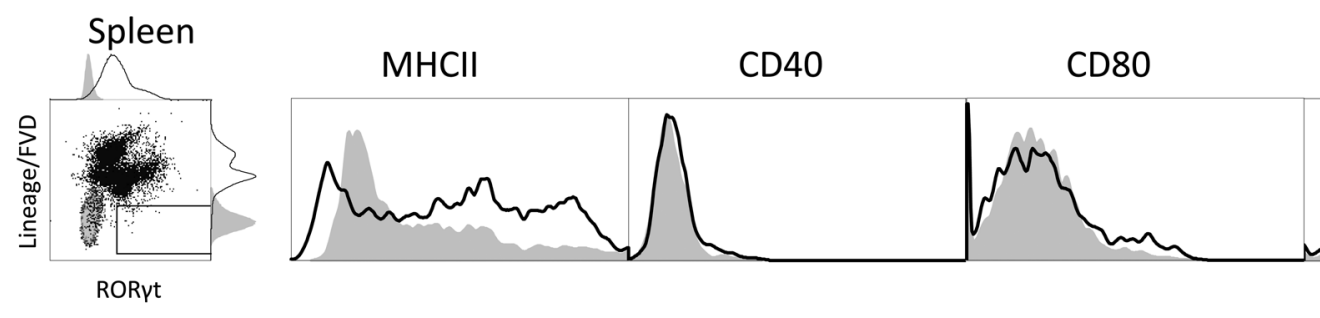

CD69
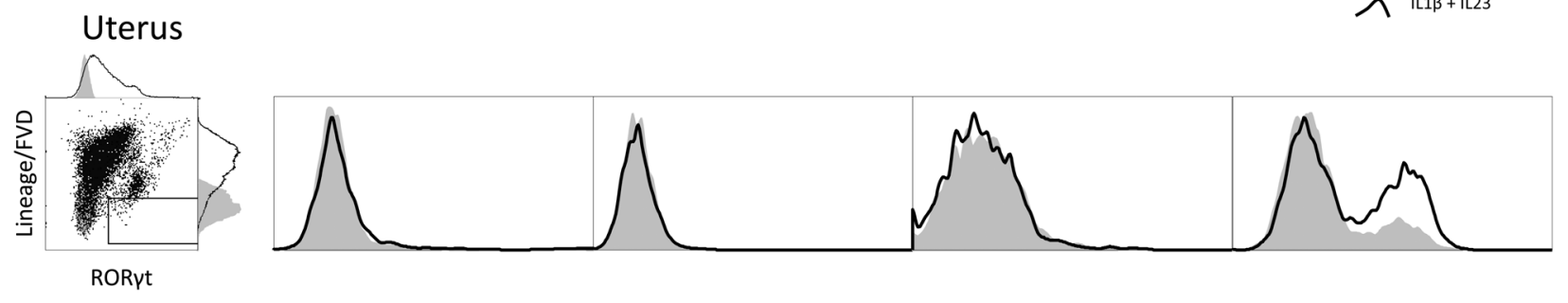

\section{B (murine)}

MHCII

CD40

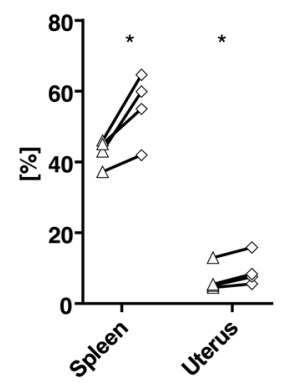

MHCII

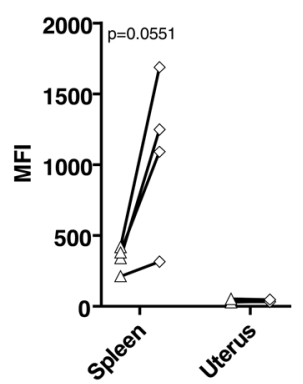

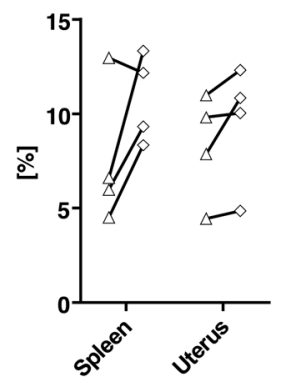

CD40

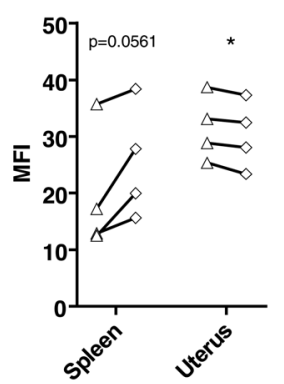

CD80

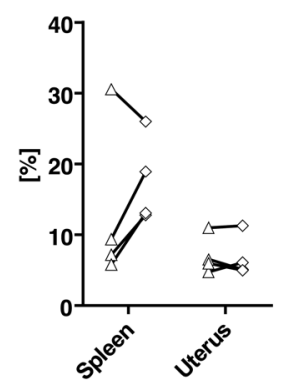

CD80

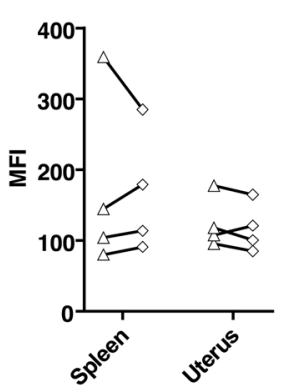

CD69

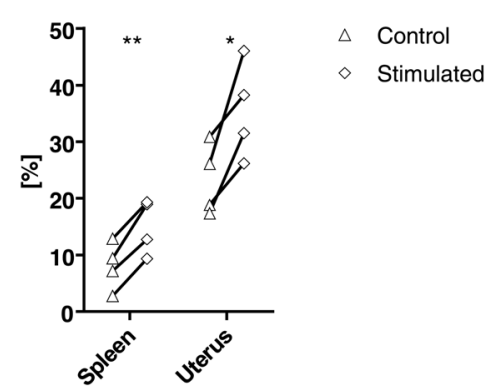

CD69

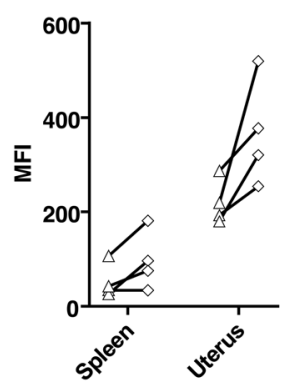

Figure 3 Uterine ILC3s have reduced antigen presentation potential than splenic ILC3s. The regulation of antigen presentation and costimulatory molecules was compared between splenic and uterine ILC3s. Therefore, spleen and uterus of pregnant C57BI/6 mice mated with BALB/c males were obtained at $17 \mathrm{dpp}$. Murine splenocytes and uterine mononuclear cells were in vitro either treated with IL-1 $\beta$ and IL-23 activating ILC3s for $48 \mathrm{~h}$ or left untreated. The expression major histocompatibility complex class II (MHCII) and costimulatory molecules CD40, CD69 and CD80, essential for antigen presentation, were determined by flow cytometry. (A) Plots show gating strategy for ILC3s (Lin- (including: CD3e, CD8a, $\mathrm{CD} 11 \mathrm{~b}, \mathrm{Ter119}, \mathrm{CD} 19) \mathrm{ROR}_{\mathrm{t}} \mathrm{t}^{+}$and overlapping histograms display fluorescence intensity. The grey area represents the non-treated control. The black line shows the activated ILC3s. (B) Mean fluorescence intensity (MFI) and proportions of expressing cells were determined. Paired data connected by the line were analyzed by paired $t$-test. ${ }^{*} P<0.05$; Data represents four independent experiments performed in triplicate.

late-pregnancy complications including preterm birth (Xu et al. 2018).

In addition to cytokine secretion, ILCs can promote or hinder adaptive immune responses by direct cellto-cell contact (Withers 2016). Splenic ILCs express membrane-bound BAFF (B-cell activating factor) and the ligands CD40L and DLL1. The contactdependent signals of these molecules stimulate $\mathrm{MZ}$ and plasma cells, promoting antibody production (von Burg et al. 2014). Although DLL1 expression on ILCs is 
A (human)

Decidua Basalis
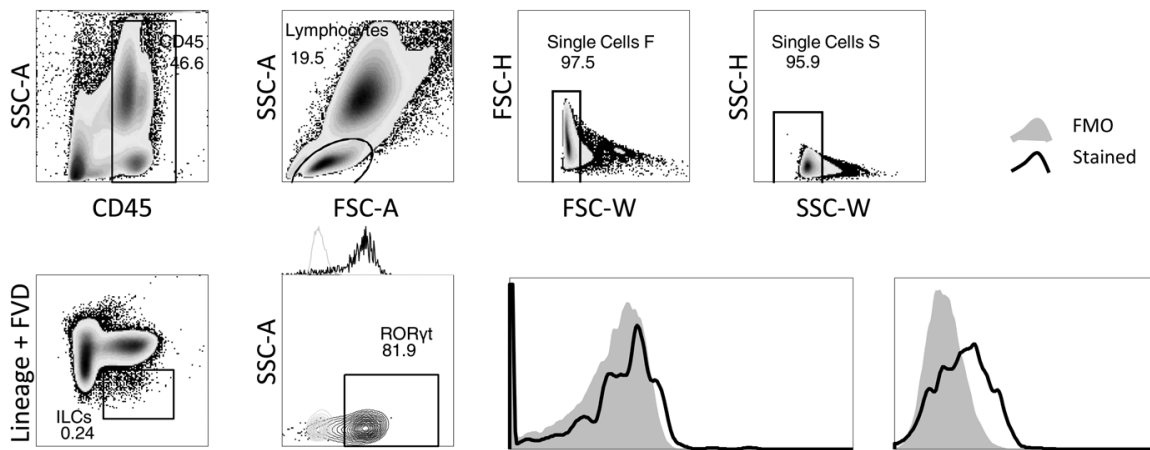

FSC-A

FSC-W

SSC-W
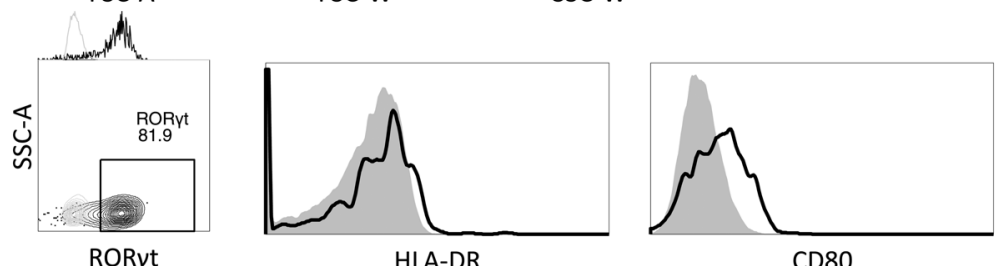

CD127

RORyt

HLA-DR

CD80

Decidua Parietalis

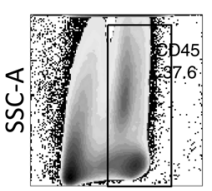

CD45

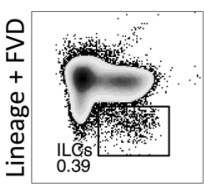

CD127

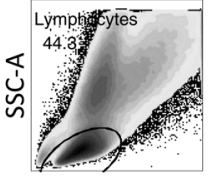

FSC-A

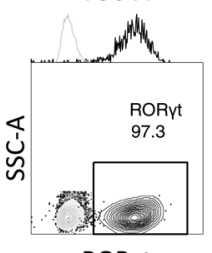

RORyt

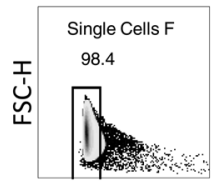

FSC-W

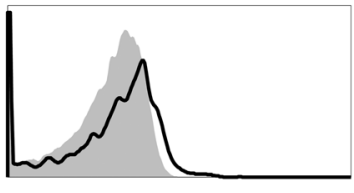

HLA-DR
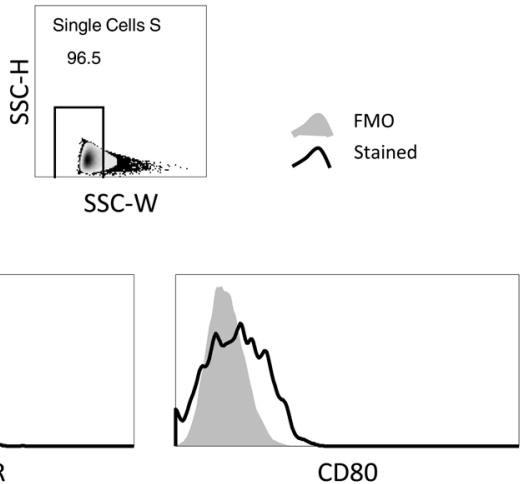

\section{B (human)}

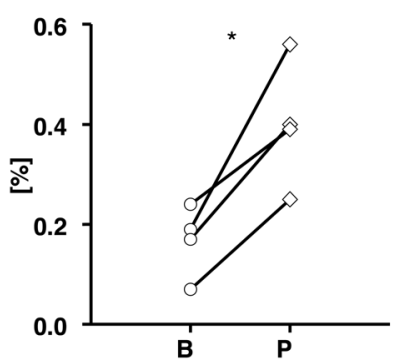

ILC3s

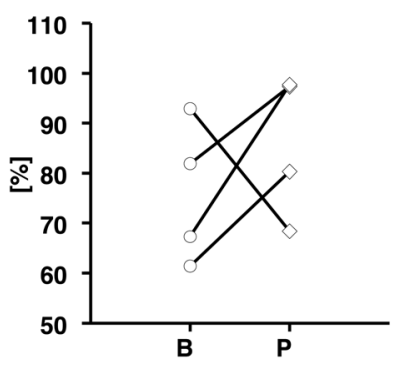

HLA-DR

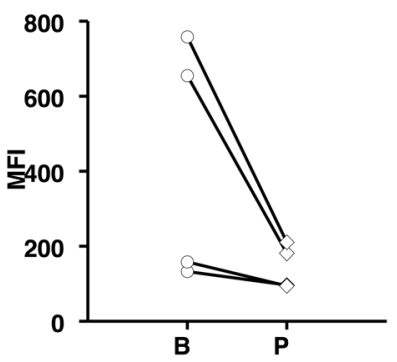

CD80

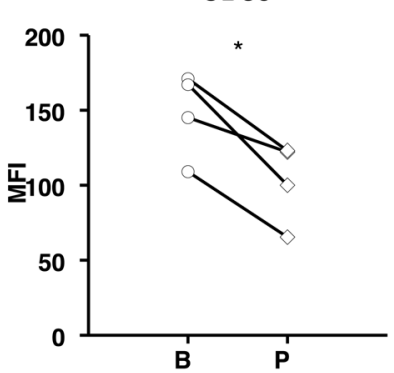

Figure 4 Human decidual ILC3 antigen presentation potential is limited and varies between compartments. Mononuclear cells were isolated from decidua basalis and parietalis from term caesarian sections. Cells were stained for flow cytometry analysis of ILC3s $\left(C D 45^{+} \mathrm{CD} 1 \mathrm{a}^{-} \mathrm{CD} 3{ }^{-}\right.$

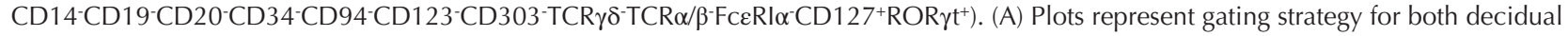
compartments. Grey areas show FMO controls. Overlapping histograms represent stained samples. (B) Analysis results comparing LC3s from decidua basalis (B) and parietalis (P) are shown. Paired data of samples from one women are connected by a line. Differences between decidual compartments were analyzed with paired $t$-tests. $* P<0.05 ; n=4$. Data represent four independent human samples.

upregulated in both murine pregnancy groups, CD40L was expressed in higher levels in POPM. Whether this is related to the differences in the immunoglobulin milieu between both groups or if it affects pregnancy outcome should be further investigated (Muzzio et al. 2016).
A remarkable aspect of the ILC biology in terms of cell-cell control of adaptive responses is their ability to act as antigen presenting cells. ILC2s as well as ILC3s process and present antigens through MHCIl complex (Oliphant et al. 2014, von Burg et al. 2014). Antigen presentation by ILC2s plays an important role in the 
A (human)

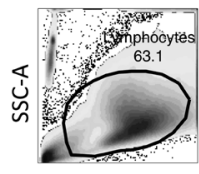

FSC-A

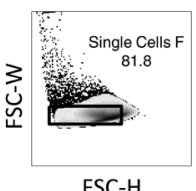

FSC-H

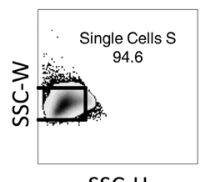

SSC-H

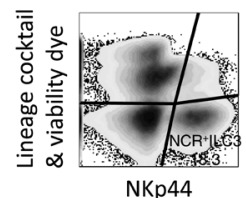

HLA-DR
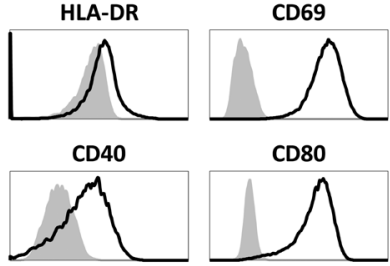

B (human)

hCG
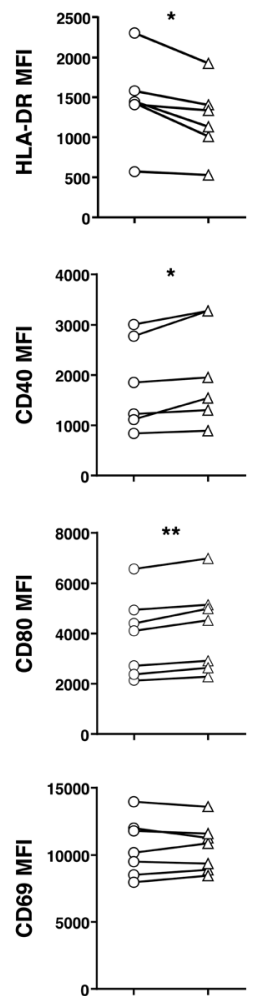

-O- CtI

$\rightarrow-200 \mathrm{U} / \mathrm{mL}$
TGF- $\beta$
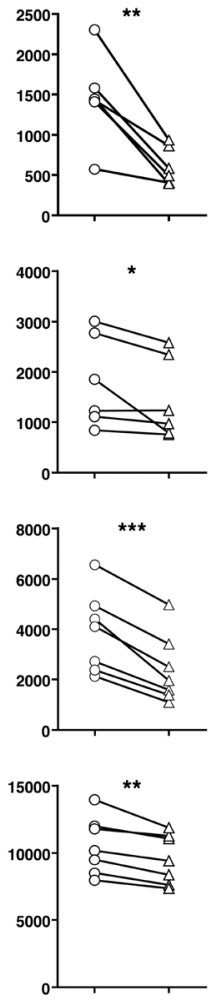

$-\mathrm{C}-\mathrm{Ctl}$

$\rightarrow 20 \mathrm{ng} / \mathrm{mL}$
Estradiol
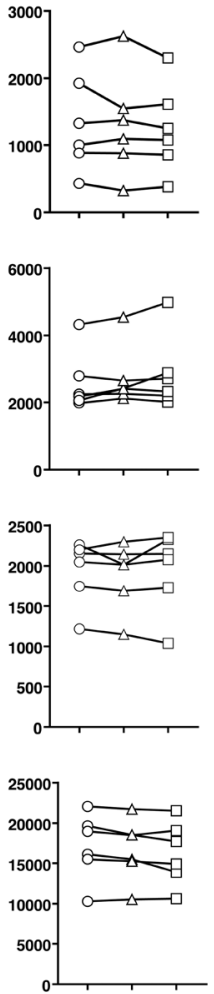

$-\infty-\mathrm{Ctl}$

$\neg 3 \mathrm{ng} / \mathrm{mL}$

마 $20 \mathrm{ng} / \mathrm{mL}$
Progesterone
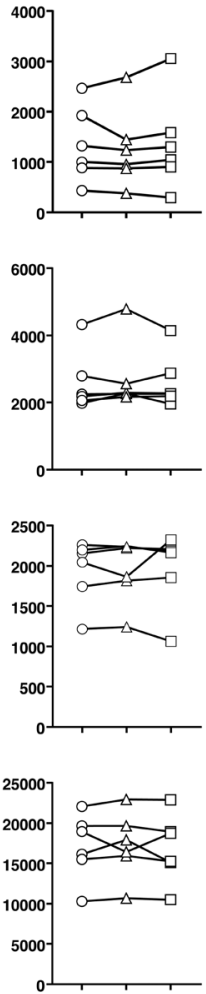

-o- Ctl

$\triangle 30 \mathrm{ng} / \mathrm{mL}$

마 $200 \mathrm{ng} / \mathrm{mL}$
VEGF
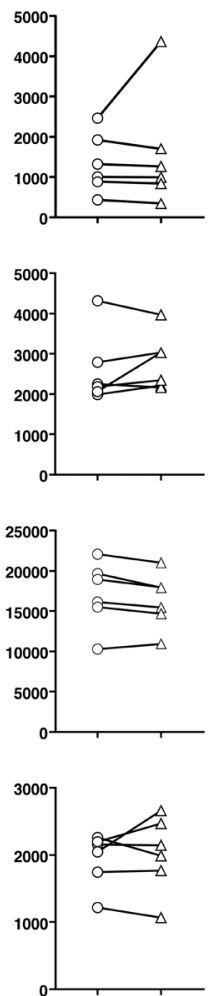

$-0-$ Ctl

$\triangle 20 \mathrm{ng} / \mathrm{mL}$

C (human)
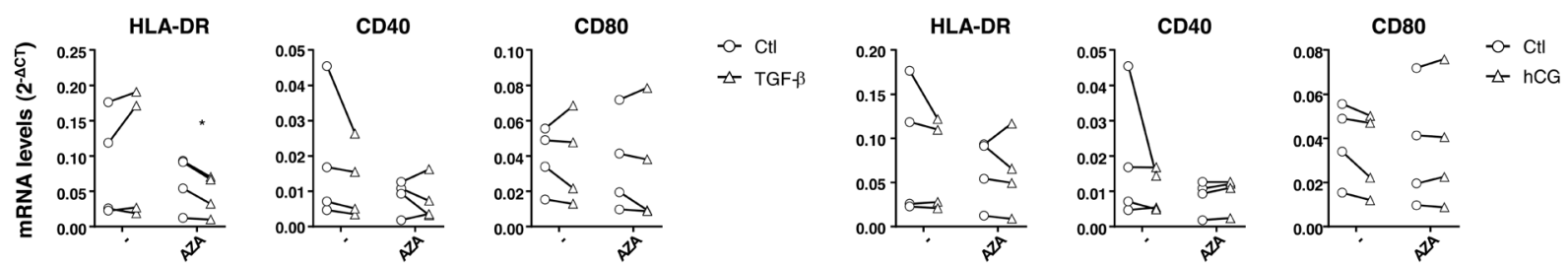

Figure 5 Pregnancy-related hormones reduce antigen presentation potential of ILC3s in vitro. In vitro-differentiated ILC3s from human stem cells were treated with either human chorionic gonadotropin (hCG; $200 \mathrm{IU} / \mathrm{mL}$ ), transforming growth factor (TGF- $\beta 1 ; 20 \mathrm{ng} / \mathrm{mL}$ ), vascular endothelial growth factor (VEGF; $20 \mathrm{ng} / \mathrm{mL}$ ) estradiol or progesterone for $72 \mathrm{~h}$. Untreated cells served as control. All cells were activated with IL-1 $\beta$ and IL-23 $(20 \mathrm{ng} / \mathrm{mL})$ for the last $18 \mathrm{~h}$ before flow cytometry analysis. (A) Plots represent gating strategy for cell sorting and flow cytometry analysis in (B). Grey areas show FMO controls. Overlapping histograms represent stained samples. (B) Overlapping histograms of Lin-NKp44 ${ }^{+}$gated cells used for analysis of surface markers on (B). Paired data of one experiment are connected by a line. Treatments with hCG, TGF- $\beta 1$ and VEGF were analyzed by paired $t$-tests. Data from stimulation with progesterone and estradiol were analyzed by one-way ANOVA (for repeated measures) with Dunnett's post test. ${ }^{*} P<0.05, * * P<0.01, * * * P<0.001 ; n \geq 6$. (C) qPCRs were performed after same culture conditions and after pretreatment with Aza, respectively. Data were analyzed by paired $t$-test. ${ }^{*} P<0.05$. Flow cytometry data was obtained from six independent experiments in duplicate. qPCR data are representative of four experiments in duplicate. 
ILC2-Th2 crosstalk, leading to the induction of Th2 responses in chronic obstructive pulmonary disease and helminth expulsion (Oliphant et al. 2014, Jiang et al. 2019). Depending on the expression pattern of costimulatory molecules CD80, CD86 and CD40, ILC3s can either promote pro-inflammatory Th1/Th17 immune responses or, as shown in the gut, actively induce tolerance to commensal bacteria (von Burg et al. 2015). A characterization of antigen presentation capacity of ILCs during pregnancy in the context of reproduction was lacking.

In order to acquire more information on the behavior of ILCs in terms of antigen presentation, we used the $\mathrm{CBA} / \mathrm{J} \times \mathrm{DBA} / 2 \mathrm{~J}$ mouse model. Here, a proinflammatory immune rejection to paternal antigens occurs (Clark et al. 2013, Muzzio et al. 2014c). The intensity of the immune answer and its impact on pregnancy outcome is thought to be influenced by the priming effect of intestinal flora (Hamilton \& Hamilton 1987, Clark et al. 2004). In our experiments, changes in the antigen presentation potential during pregnancy were particularly remarkable. Here, we observed an increased expression of $\mathrm{Lin}^{-\mathrm{CD}} 127^{+} \mathrm{CRTH} 2^{+}$and $\mathrm{Lin}^{-} \mathrm{CD} 127^{+} \mathrm{CRTH} 2^{-\mathrm{NKp}} 44^{-} \mathrm{CD} 117^{+}$cells in POPM compared to NPM. As ILC2s and ILC3s are characterized to display these phenotypes, we took a deeper look into the antigen presentation potential of ILC2s and ILC3s. Here, healthy pregnancies were accompanied by a lower antigen presentation potential as compared to NPM mice, suggesting a tolerogenic adaptation during pregnancy. Furthermore, POPM had higher antigen presentation potential in ILCs than GOPM. This suggests that higher ILC antigen presentation might influence pregnancy outcome. We speculate that this could boost immune responses against intestinal flora which are thought to be involved in the resorptive phenotype in those mice (Clark et al. 2002).

MHCII expression on ILC2s is associated to promotion of Th2 responses, which dominate during the maintenance of pregnancy (Oliphant et al. 2014, Jiang et al. 2019). However, we observed that during GOPM pregnancies, where a Th2 tone prevails, the expression of MHCII on ILC2s was reduced. On the other hand, MHCII expression on ILC3s is associated with the promotion of Th1 and Th17 responses. Th1 and Th17 responses characterize POPM pregnancies, where the expression of MHCII on ILC3s was indeed increased. The reduced $\mathrm{MHCll}$ expression on ILC3 in GOPM suggests a pregnancy-mediated limitation of the antigen presentation potential. Considering the adaptations of splenic and intestinal ILC3 in terms of antigen presentation potential during pregnancy, we moved forward to investigate the phenotype of local ILC3s at the fetomaternal interface and their regulation by local and pregnancy-related factors.

von Burg et al. (2014) showed that there are striking differences between ILC3s thatpromotepro-inflammatory immune responses (e.g. splenic) and intestinal ILC3s, where commensal bacteria tolerance is essential. Similarly, we showed that uterine ILC3s phenotype differs significantly from their splenic counterparts in their reduced antigen presentation potential. In contrast to intestinal active tolerance driven by higher $\mathrm{MHCII}$ and low costimulatory molecule expression, we observed a reduction of antigen presentation potential by low $\mathrm{MHCll}$ expression and refractory response to pro-inflammatory stimuli. This phenomenon could be interpreted as a passive tolerance mechanism during pregnancy.

Analyses of meconium indicate that the infant gut may be colonized in utero (Collado et al. 2016). Vaginal, oral and gut maternal microbiomes are thought to represent the source of non-pathogenic intrauterine microbes that are later transferred to the infant (Walker et al. 2017). In order to allow bacteria transfer without initiation of a proinflammatory response that would threaten pregnancy wellbeing, immune cells should moderate responses against these bacteria. The pattern recognition receptor family TLR (Toll like receptors) is expressed in several cells of the female reproductive tract. Altered expression of TLRs has been linked to pregnancy complications such as preterm birth and pre-eclampsia (Riley \& Nelson 2010, Amirchaghmaghi et al. 2013).

TLRs permit the detection of live and dead bacteria as well as bacterial products (Ugolini et al. 2018). Despite the mere presence of bacterial products at the fetomaternal interface, it is important how these are recognized and whether they represent serious threats. The subsequent activation of cells of the adaptive immune system plays an important role determining the extent of the elicited response and the consequences on pregnancy outcome. A reduced antigen presentation, as we observed in splenic, intestinal and uterine ILCs during pregnancy, may represent a mechanism to avoid excessive T-cell activation. This would contribute to a tolerogenic microenvironment that facilitates bacteria translocation and further transfer to the fetus.

TGF- $\beta 1$ is a multifunctional anti-inflammatory cytokine implicated in induction of tolerance against commensal bacteria in the gut (Bauché \& Marie 2017). It is also involved in the development and remodeling of reproductive tissues (Ingman \& Robertson 2009). TGF$\beta 1$ is thought to facilitate implantation and to regulate endometrial function and decidualization. Furthermore, TGF- $\beta 1$ plays a specific role during pregnancy, promoting blastocyst proliferation and development and regulating trophoblast growth, migration and invasiveness. Finally, TGF- $\beta 1$ promotes immune tolerance, inhibiting Th1 response and promoting decidual phenotype in the cytotoxic arm of the ILCs, the NK cells (Jones et al. 2006).

Our mouse data suggested that uterine environment limits antigen presentation potential of ILC3s. Apart from its role in reproduction, TGF- $\beta 1$ controls ILC3s development and cytokine expression pattern 
(Viant et al. 2016). In our experiments, TGF- $\beta 1$ induced a tolerogenic phenotype on ILC3s as characterized by a reduction of HLA-DR and costimulatory molecules expression.

HCG influences many aspects of placentation, including trophoblast invasion and vascularization as well as immune adaptations, especially during early pregnancy development (Evans 2016). Similar to TGF$\beta 1$ treatment, hCG can reduce antigen presentation potential of ILC3s by downregulation of HLA-DR expression. In contrast, the expression pattern of costimulatory molecules was different from the treatment with TGF- $\beta 1$ and was accompanied by an upregulation of CD40 and CD80 expression. We also observed that the regulatory effect of hCG and TGF- $\beta 1$ were more evident at protein surface expression than at transcript level. Here, epigenetic control may be playing an important role, as we could replicate some of the effects observed at protein level after pre-treatment with the demethylating agent Aza. Functional aspects of CD40 and CD80 expression on ILC3s independent of antigen presentation remain still unclear and deserve to be explored in future studies. Similarly, their relevance in the immune homeostasis that provides defense without detriment to fetal and eventually local microbiota tolerance needs to be further investigated.

The sex hormones progesterone and estradiol participate in immune tolerance mechanisms, as the induction of T-cell mediated tolerance (Mao et al. 2010, Nancy \& Erlebacher 2014). In our experiment, in contrast to hCG and TGF- $\beta 1$, progesterone and estradiol did not induce changes ILC3 in the expression of HLA-DR or costimulatory molecules. Progesterone and estradiol change during menstrual cycle, whereas endometrial TGF- $\beta 1$ secretion remains stable and increases dramatically after implantation (Jones et al. 2006). Similarly, hCG is produced by trophoblasts and therefore secreted after fertilization (Mao et al. 2010, Kumar \& Magon 2012, Hepworth et al. 2013). As ILC3 antigen presentation potential is not affected by progesterone or estradiol, it possibly remains stable during menstrual cycle and is rather regulated in case of a successful fertilization and subsequent implantation and therefore important for pregnancy wellbeing (Mao et al. 2010, Nancy \& Erlebacher 2014).

We aimed to give insights into the composition of circulating ILCs during human pregnancies using a well-accepted simplified strategy (Bernink et al. 2013, Loyon et al. 2019). Our results encourage an extended detailed characterization of the phenotypic properties of circulating ILCs. In this context, it remains unclear if circulating ILCs would reflect local uterine or peripheral conditions. Moreover, it has been shown that circulating Lin-CD $127^{+} \mathrm{CD} 117^{+}$cells have immature characteristics, representing ILC progenitors rather than differentiated ILC3s (Lim et al. 2017). Similarly, because of their high plasticity and the lack of specific markers, the definition of ILC1 is still a matter of debate (O'Sullivan 2019). Recent developments in the transcriptomic and flow cytometry based clustering algorithms permit the generation and the analysis of valuable amounts of data to further characterize existing and novel subsets within the ILC compartment (Vazquez et al. 2019). In this concern, an in-depth characterization could provide valuable information to develop diagnostic tools throughout pregnancy progress.

Our data indicate that ILC redistribution occurs during pregnancy and unveils regulations in $\mathrm{MHCII}$ expression on the ILC3 subset. Moreover, MHCII expression seemed to be strongly regulated at the fetomaternal interface, as observed in murine uterine ILC3s stimulated ex vivo and later through in vitro experiments involving treatment with hormones. It is important to note that MHCII expression per se does not imply an actual presentation of antigens and may simply depict an activation status as observed in human T cells (Arruvito et al. 2014). Our data, in this sense, encourage the use of mouse models to better determine antigen presentation capacity of ILC3s during pregnancy (e.g. MHCII ${ }^{\Delta l L C}$, Hepworth et al. 2013). Furthermore, no further studies concerning uterine ILCs as antigen presenting cells have been performed to date. Finally, whether the reduction of the antigen presentation presents an advantage to tolerate fetal antigens or to better accommodate changes in the gut or uterine microbiota during pregnancy needs to be clarified.

Overall, our data indicate that healthy pregnancy is associated with a decrease of MHCll expression on ILC3s, which in the context of fetal tolerance during pregnancy is suggestive of a reduction in their antigen presentation potential.

\section{Supplementary materials}

This is linked to the online version of the paper at https://doi. org/10.1530/REP-19-0554.

\section{Declaration of interest}

The authors declare that there is no conflict of interest that could be perceived as prejudicing the impartiality of the research reported.

\section{Funding}

This study was supported by intramural funding from Greifswald University.

\section{Author contribution statement}

R E performed experiments, analyzed data and contributed to the elaboration of the manuscript. J E, D K and $\mathrm{K} \mathrm{H}$ performed experiments. M Z contributed with reagents, the design of 
experiments and the writing of the manuscript. D M conceived and designed the experiments, analyzed data, wrote the paper and supervised the work.

\section{Acknowledgments}

The authors thank the Landesgraduiertenförderung Mecklenburg-Vorpommern for the financial support to $\mathrm{R}$. The authors also thank Ilona Bich, MD, and Dominika Trojnarska, $\mathrm{MD}$, and delivery room staff for collecting human samples. A special thanks to Marcus Vollmer from the Institute of Bioinformatics for his expert statistical advice.

\section{References}

Aagaard K, Ma J, Antony KM, Ganu R, Petrosino J \& Versalovic J 2014 The placenta harbors a unique microbiome. Science Translational Medicine 6 237ra65. (https://doi.org/10.1126/scitranslmed.3008599)

Aghaeepour N, Ganio EA, Mcllwain D, Tsai AS, Tingle M, Van Gassen S, Gaudilliere DK, Baca Q, McNeil L, Okada R et al. 2017 An immune clock of human pregnancy. Science Immunology 2 eaan2946. (https:// doi.org/10.1126/sciimmunol.aan2946)

Ahmed A, Singh J, Khan Y, Seshan SV \& Girardi G 2010 A new mouse model to explore therapies for preeclampsia. PLOS ONE 5 e13663. (https://doi.org/10.1371/journal.pone.0013663)

Amirchaghmaghi E, Taghavi SA, Shapouri F, Saeidi S, Rezaei A \& Aflatoonian R 2013 The role of toll like receptors in pregnancy. International Journal of Fertility and Sterility 7 147-154.

Arruvito L, Payaslian F, Baz P, Podhorzer A, Billordo A, Pandolfi J, Semeniuk G, Arribalzaga E \& Fainboim L 2014 Identification and clinical relevance of naturally occurring human $\mathrm{CD} 8+\mathrm{HLA}-\mathrm{DR}+$ regulatory $\mathrm{T}$ cells. Journal of Immunology 193 4469-4476. (https://doi.org/10.4049/ jimmunol.1401490)

Bartemes K, Chen CC, lijima K, Drake L \& Kita H 2018 IL-33-responsive group 2 innate lymphoid cells are regulated by female sex hormones in the uterus. Journal of Immunology 200 229-236. (https://doi. org/10.4049/jimmunol.1602085)

Bartmann C, Segerer SE, Rieger L, Kapp M, Sutterlin M \& Kammerer U 2014 Quantification of the predominant immune cell populations in decidua throughout human pregnancy. American Journal of Reproductive Immunology 71 109-119. (https://doi.org/10.1111/aji.12185)

Bauché D \& Marie JC 2017 Transforming growth factor beta: a master regulator of the gut microbiota and immune cell interactions. Clinical and Translational Immunology 6 e136. (https://doi.org/10.1038/cti.2017.9)

Bernink JH, Peters CP, Munneke M, te Velde AA, Meijer SL, Weijer K, Hreggvidsdottir HS, Heinsbroek SE, Legrand N, Buskens CJ et al. 2013 Human type 1 innate lymphoid cells accumulate in inflamed mucosal tissues. Nature Immunology 14 221-229. (https://doi.org/10.1038/ni.2534)

Bonney EA \& Brown SA 2014 To drive or be driven: the path of a mouse model of recurrent pregnancy loss. Reproduction 147 R153-R167. (https://doi.org/10.1530/REP-13-0583)

Chaouat G, Assal Meliani A, Martal J, Raghupathy R, Elliott JF, Mosmann T \& Wegmann TG 1995 IL-10 prevents naturally occurring fetal loss in the $\mathrm{CBA} \times \mathrm{DBA} / 2$ mating combination, and local defect in IL-10 production in this abortion-prone combination is corrected by in vivo injection of IFN-tau. Journal of Immunology 154 4261-4268. (https:// doi.org/10.4049/jimmunol.175.5.3447-d)

Clark DA, McDermott MR \& Szewczuk MR 1980 Impairment of hostversus-graft reaction in pregnant mice. II. Selective suppression of cytotoxic T-cell generation correlates with soluble suppressor activity and with successful allogeneic pregnancy. Cellular Immunology 52 106-118. (https://doi.org/10.1016/0008-8749(80)90404-9)

Clark DA, Chaput A \& Tutton D 1986 Active suppression of host-vs-graft reaction in pregnant mice. VII. Spontaneous abortion of allogeneic CBA/J $x \mathrm{DBA} / 2$ fetuses in the uterus of $\mathrm{CBA} / \mathrm{J}$ mice correlates with deficient non-T suppressor cell activity. Journal of Immunology 136 1668-1675.

Clark DA, Chaouat G \& Gorczynski RM 2002 Thinking outside the box: mechanisms of environmental selective pressures on the outcome of the materno-fetal relationship. American Journal of Reproductive Immunology $47 \quad 275-282 . \quad$ (https://doi.org/10.1034/j.16000897.2002.01093.x)

Clark DA, Manuel J, Lee L, Chaouat G, Gorczynski RM \& Levy GA 2004 Ecology of danger-dependent cytokine-boosted spontaneous abortion in the CBA $\times$ DBA/2 mouse model. I. Synergistic effect of LPS and (TNF-alpha + IFN-gamma) on pregnancy loss. American Journal of Reproductive Immunology 52 370-378. (https://doi.org/10.1111/j.16000897.2004.00237.x)

Clark DA, Rahmati M, Gohner C, Bensussan A, Markert UR \& Chaouat G 2013 Seminal plasma peptides may determine maternal immune response that alters success or failure of pregnancy in the abortion-prone CBAxDBA/2 model. Journal of Reproductive Immunology 99 46-53. (https://doi.org/10.1016/j.jri.2013.03.006)

Collado MC, Rautava S, Aakko J, Isolauri E \& Salminen S 2016 Human gut colonisation may be initiated in utero by distinct microbial communities in the placenta and amniotic fluid. Scientific Reports 6 23129. (https:// doi.org/10.1038/srep23129)

Colonna M 2018 Innate lymphoid cells: diversity, plasticity, and unique functions in immunity. Immunity 48 1104-1117. (https://doi. org/10.1016/j.immuni.2018.05.013)

Croxatto D, Micheletti A, Montaldo E, Orecchia P, Loiacono F, Canegallo F, Calzetti F, Fulcheri E, Munari E, Zamo A et al. 2016 Group 3 innate lymphoid cells regulate neutrophil migration and function in human decidua. Mucosal Immunology 9 1372-1383. (https://doi.org/10.1038/ mi.2016.10)

Diefenbach A, Colonna M \& Romagnani C 2017 The ILC world revisited. Immunity 46 327-332. (https://doi.org/10.1016/j.immuni.2017.03.008)

Dixon ME, Chien EK, Osol G, Callas PW \& Bonney EA 2006 Failure of decidual arteriolar remodeling in the $\mathrm{CBA} / \mathrm{J} \times \mathrm{DBA} / 2$ murine model of recurrent pregnancy loss is linked to increased expression of tissue inhibitor of metalloproteinase 2 (TIMP-2). American Journal of Obstetrics and Gynecology 194 113-119. (https://doi.org/10.1016/j. ajog.2005.06.063)

Doisne JM, Balmas E, Boulenouar S, Gaynor LM, Kieckbusch J, Gardner L, Hawkes DA, Barbara CF, Sharkey AM, Brady HJ et al. 2015 Composition, development, and function of uterine innate lymphoid cells. Journal of Immunology 195 3937-3945. (https://doi.org/10.4049/ jimmunol.1500689)

Doyle RM, Alber DG, Jones HE, Harris K, Fitzgerald F, Peebles D \& Klein N 2014 Term and preterm labour are associated with distinct microbial community structures in placental membranes which are independent of mode of delivery. Placenta 35 1099-1101. (https://doi.org/10.1016/j. placenta.2014.10.007)

Erlebacher A, Vencato D, Price KA, Zhang D \& Glimcher LH 2007 Constraints in antigen presentation severely restrict $\mathrm{T}$ cell recognition of the allogeneic fetus. Journal of Clinical Investigation 117 1399-1411. (https://doi.org/10.1172/JCl28214)

Evans J 2016 Hyperglycosylated hCG: a unique human implantation and invasion factor. American Journal of Reproductive Immunology 75 333-340. (https://doi.org/10.1111/aji.12459)

Girardi G, Yarilin D, Thurman JM, Holers VM \& Salmon JE 2006 Complement activation induces dysregulation of angiogenic factors and causes fetal rejection and growth restriction. Journal of Experimental Medicine 203 2165-2175. (https://doi.org/10.1084/jem.20061022)

Hamilton MS \& Hamilton BL 1987 Environmental influences on immunologically associated spontaneous abortion in CBA/J mice. Journal of Reproductive Immunology 11 237-241. (https://doi. org/10.1016/0165-0378(87)90060-x)

Hepworth MR, Monticelli LA, Fung TC, Ziegler CG, Grunberg S, Sinha R, Mantegazza AR, Ma HL, Crawford A, Angelosanto JM et al. 2013 Innate lymphoid cells regulate CD4+ T-cell responses to intestinal commensal bacteria. Nature 498 113-117. (https://doi.org/10.1038/nature12240)

Ingman WV \& Robertson SA 2009 The essential roles of TGFB1 in reproduction. Cytokine and Growth Factor Reviews 20 233-239. (https://doi.org/10.1016/j.cytogfr.2009.05.003)

Jiang M, Liu H, Li Z, Wang J, Zhang F, Cao K, Li F \& Ding J 2019 ILC2s induce adaptive Th2-type immunity in acute exacerbation of chronic obstructive pulmonary disease. Mediators of Inflammation 2019 3140183. (https://doi.org/10.1155/2019/3140183)

Jin LP, Zhou YH, Wang MY, Zhu XY \& Li DJ 2005 Blockade of CD80 and CD86 at the time of implantation inhibits maternal rejection to the 
allogeneic fetus in abortion-prone matings. Journal of Reproductive Immunology 65 133-146. (https://doi.org/10.1016/j.jri.2004.08.009)

Jones RL, Stoikos C, Findlay JK \& Salamonsen LA 2006 TGF-beta superfamily expression and actions in the endometrium and placenta. Reproduction 132 217-232. (https://doi.org/10.1530/rep.1.01076)

Kumar P \& Magon N 2012 Hormones in pregnancy. Nigerian Medical Journal 53 179-183. (https://doi.org/10.4103/0300-1652.107549)

Li Y, Lopez GE, Vazquez J, Sun Y, Chavarria M, Lindner PN, Fredrickson S, Karst N \& Stanic AK 2018 Decidual-placental immune landscape during syngeneic murine pregnancy. Frontiers in Immunology 9 2087. (https:// doi.org/10.3389/fimmu.2018.02087)

Lim AI, Li Y, Lopez-Lastra S, Stadhouders R, Paul F, Casrouge A, Serafini N, Puel A, Bustamante J, Surace L et al. 2017 Systemic human ILC precursors provide a substrate for tissue ILC differentiation. Cell 168 1086-1100.e10. (https://doi.org/10.1016/j.cell.2017.02.021)

Loyon R, Jary M, Salome B, Gomez-Cadena A, Galaine J, Kroemer M, Romero P, Trabanelli S, Adotevi O, Borg C et al. 2019 Peripheral innate lymphoid cells are increased in first line metastatic colorectal carcinoma patients: a negative correlation with Th1 immune responses. Frontiers in Immunology 10 2121. (https://doi.org/10.3389/fimmu.2019.02121)

Magri G, Miyajima M, Bascones S, Mortha A, Puga I, Cassis L, Barra CM, Comerma L, Chudnovskiy A, Gentile M et al. 2014 Innate lymphoid cells integrate stromal and immunological signals to enhance antibody production by splenic marginal zone B cells. Nature Immunology $\mathbf{1 5}$ 354-364. (https://doi.org/10.1038/ni.2830)

Male V, Hughes T, McClory S, Colucci F, Caligiuri MA \& Moffett A 2010 Immature NK cells, capable of producing IL-22, are present in human uterine mucosa. Journal of Immunology 185 3913-3918. (https://doi. org/10.4049/jimmunol.1001637)

Mao G, Wang J, Kang Y, Tai P, Wen J, Zou Q, Li G, Ouyang H, Xia G \& Wang B 2010 Progesterone increases systemic and local uterine proportions of CD4+CD25+ Treg cells during midterm pregnancy in mice. Endocrinology 151 5477-5488. (https://doi.org/10.1210/en.20100426)

McKelvey KJ, Yenson VM, Ashton AW, Morris JM \& McCracken SA 2016 Embryonic/fetal mortality and intrauterine growth restriction is not exclusive to the CBA/J sub-strain in the CBA $x$ DBA model. Scientific Reports 6 35138. (https://doi.org/10.1038/srep35138)

Mor G, Cardenas I, Abrahams V \& Guller S 2011 Inflammation and pregnancy: the role of the immune system at the implantation site. Annals of the New York Academy of Sciences 1221 80-87. (https://doi. org/10.1111/j.1749-6632.2010.05938.x)

Mor G, Aldo P \& Alvero AB 2017 The unique immunological and microbial aspects of pregnancy. Nature Reviews. Immunology 17 469-482. (https:// doi.org/10.1038/nri.2017.64)

Moretta F, Petronelli F, Lucarelli B, Pitisci A, Bertaina A, Locatelli F, Mingari MC, Moretta L \& Montaldo E 2016 The generation of human innate lymphoid cells is influenced by the source of hematopoietic stem cells and by the use of G-CSF. European Journal of Immunology $\mathbf{4 6}$ 1271-1278. (https://doi.org/10.1002/eji.201546079)

Munneke JM, Björklund AT, Mjösberg JM, Garming-Legert K, Bernink JH, Blom B, Huisman C, van Oers MH, Spits H, Malmberg KJ et al. 2014 Activated innate lymphoid cells are associated with a reduced susceptibility to graft-versus-host disease. Blood 124 812-821. (https:// doi.org/10.1182/blood-2013-11-536888)

Muzzio D, Zygmunt M \& Jensen F 2014a The role of pregnancy-associated hormones in the development and function of regulatory B cells. Frontiers in Endocrinology 5 39. (https://doi.org/10.3389/fendo.2014.00039)

Muzzio DO, Soldati R, Ehrhardt J, Utpatel K, Evert M, Zenclussen AC, Zygmunt M \& Jensen F $2014 b$ B cell development undergoes profound modifications and adaptations during pregnancy in mice. Biology of Reproduction 91 115. (https://doi.org/10.1095/biolreprod.114.122366)

Muzzio DO, Soldati R, Rolle L, Zygmunt M, Zenclussen AC \& Jensen F 2014C B-1a B cells regulate T cell differentiation associated with pregnancy disturbances. Frontiers in Immunology 5 6. (https://doi. org/10.3389/fimmu.2014.00006)

Muzzio DO, Ziegler KB, Ehrhardt J, Zygmunt M \& Jensen F 2016 Marginal zone B cells emerge as a critical component of pregnancy well-being. Reproduction 151 29-37. (https://doi.org/10.1530/REP-15-0274)

Nancy P \& Erlebacher A 2014 T cell behavior at the maternal-fetal interface. International Journal of Developmental Biology 58 189-198. (https://doi. org/10.1387/ijdb.140054ae)
Napso T, Yong HEJ, Lopez-Tello J \& Sferruzzi-Perri AN 2018 The role of placental hormones in mediating maternal adaptations to support pregnancy and lactation. Frontiers in Physiology 9 1091. (https://doi. org/10.3389/fphys.2018.01091)

Oliphant CJ, Hwang YY, Walker JA, Salimi M, Wong SH, Brewer JM, Englezakis A, Barlow JL, Hams E, Scanlon ST et al. 2014 MHCIl-mediated dialog between group 2 innate lymphoid cells and CD4(+) T cells potentiates type 2 immunity and promotes parasitic helminth expulsion. Immunity 41 283-295. (https://doi.org/10.1016/j.immuni.2014.06.016)

O'Sullivan TE 2019 Dazed and confused: NK cells. Frontiers in Immunology 10 2235. (https://doi.org/10.3389/fimmu.2019.02235)

Packhäuser KRH, Roman-Sosa G, Ehrhardt J, Kruger D, Zygmunt M \& Muzzio DO 2017 A kinetic study of CD83 reveals an upregulation and higher production of sCD83 in lymphocytes from pregnant mice. Frontiers in Immunology 8 486. (https://doi.org/10.3389/fimmu.2017.00486)

Raghupathy $\mathbf{R} 1997$ Th1-type immunity is incompatible with successful pregnancy. Immunology Today 18 478-482. (https://doi.org/10.1016/ s0167-5699(97)01127-4)

Riley JK \& Nelson DM 2010 Toll-like receptors in pregnancy disorders and placental dysfunction. Clinical Reviews in Allergy and Immunology 39 185-193. (https://doi.org/10.1007/s12016-009-8178-2)

Robinette ML \& Colonna M 2016 Innate lymphoid cells and the MHC. HLA 87 5-11. (https://doi.org/10.1111/tan.12723)

Romero R, Gotsch F, Pineles B \& Kusanovic JP 2007 Inflammation in pregnancy: its roles in reproductive physiology, obstetrical complications, and fetal injury. Nutrition Reviews 65 S194-S202. (https://doi.org/10.1111/j.1753-4887.2007.tb00362.x)

Satokari R, Gronroos T, Laitinen K, Salminen S \& Isolauri E 2009 Bifidobacterium and Lactobacillus DNA in the human placenta. Letters in Applied Microbiology 48 8-12. (https://doi.org/10.1111/j.1472765X.2008.02475.x)

Scifres CM \& Nelson DM 2009 Intrauterine growth restriction, human placental development and trophoblast cell death. Journal of Physiology 587 3453-3458. (https://doi.org/10.1113/jphysiol.2009.173252)

Slutsky R, Romero R, Xu Y, Galaz J, Miller D, Done B, Tarca AL, Gregor S, Hassan SS, Leng Y et al. 2019 Exhausted and senescent T cells at the maternal-fetal interface in preterm and term labor. Journal of Immunology Research 2019 3128010. (https://doi.org/10.1155/2019/3128010)

Solders M, Gorchs L, Gidlof S, Tiblad E, Lundell AC \& Kaipe H 2017 Maternal adaptive immune cells in decidua parietalis display a more activated and coinhibitory phenotype compared to decidua basalis. Stem Cells International 2017 8010961. (https://doi.org/10.1155/2017/8010961)

Steel JH, Malatos S, Kennea N, Edwards AD, Miles L, Duggan P, Reynolds PR, Feldman RG \& Sullivan MH 2005 Bacteria and inflammatory cells in fetal membranes do not always cause preterm labor. Pediatric Research 57 404-411. (https://doi.org/10.1203/01.PDR.0000153869.96337.90)

Stout MJ, Conlon B, Landeau M, Lee I, Bower C, Zhao Q, Roehl KA, Nelson DM, Macones GA \& Mysorekar IU 2013 Identification of intracellular bacteria in the basal plate of the human placenta in term and preterm gestations. American Journal of Obstetrics and Gynecology 208 226.e1-226.e7. (https://doi.org/10.1016/j.ajog.2013.01.018)

Sykes L, Macintyre DA, Yap XJ, Teoh TG \& Bennett PR 2012 The Th1:th2 dichotomy of pregnancy and preterm labour. Mediators of Inflammation 2012 967629. (https://doi.org/10.1155/2012/967629)

Ugolini M, Gerhard J, Burkert S, Jensen KJ, Georg P, Ebner F, Volkers SM, Thada S, Dietert K, Bauer L et al. 2018 Recognition of microbial viability via TLR8 drives TFH cell differentiation and vaccine responses. Nature Immunology 19 386-396. (https://doi.org/10.1038/s41590-018-0068-4)

Vacca P, Montaldo E, Croxatto D, Loiacono F, Canegallo F, Venturini PL, Moretta L \& Mingari MC 2015 Identification of diverse innate lymphoid cells in human decidua. Mucosal Immunology 8 254-264. (https://doi. org/10.1038/mi.2014.63)

Vazquez J, Chavarria M, Li Y, Lopez GE \& Stanic AK 2018 Computational flow cytometry analysis reveals a unique immune signature of the human maternal-fetal interface. American Journal of Reproductive Immunology 79. (https://doi.org/10.1111/aji.12774)

Vazquez J, Chasman DA, Lopez GE, Tyler CT, Ong IM \& Stanic AK 2019 Transcriptional and functional programming of decidual innate lymphoid cells. Frontiers in Immunology 10 3065. (https://doi.org/10.3389/ fimmu.2019.03065)

Viant C, Rankin LC, Girard-Madoux MJ, Seillet C, Shi W, Smyth MJ, Bartholin L, Walzer T, Huntington ND, Vivier E et al. 2016 Transforming 
growth factor-beta and Notch ligands act as opposing environmental cues in regulating the plasticity of type 3 innate lymphoid cells. Science Signaling 9 ra46. (https://doi.org/10.1126/scisignal.aaf2176)

von Burg N, Chappaz S, Baerenwaldt A, Horvath E, Bose Dasgupta S Ashok D, Pieters J, Tacchini-Cottier F, Rolink A, Acha-Orbea H et al. 2014 Activated group 3 innate lymphoid cells promote T-cell-mediated immune responses. PNAS 111 12835-12840. (https://doi.org/10.1073/ pnas.1406908111)

von Burg N, Turchinovich G \& Finke D 2015 Maintenance of immune homeostasis through ILC/T cell interactions. Frontiers in Immunology $\mathbf{6}$ 416. (https://doi.org/10.3389/fimmu.2015.00416)

Walker RW, Clemente JC, Peter I \& Loos RJF 2017 The prenatal gut microbiome: are we colonized with bacteria in utero? Pediatric Obesity 12 (Supplement 1) 3-17. (https://doi.org/10.1111/ijpo.12217)

Whitley GS \& Cartwright JE 2009 Trophoblast-mediated spiral artery remodelling: a role for apoptosis. Journal of Anatomy 215 21-26. (https://doi.org/10.1111/j.1469-7580.2008.01039.x)

Withers DR 2016 Innate lymphoid cell regulation of adaptive immunity. Immunology 149 123-130. (https://doi.org/10.1111/imm.12639)
Xiong T \& Turner JE 2018 Innate lymphoid cells in autoimmunity and chronic inflammatory diseases. Seminars in Immunopathology $\mathbf{4 0}$ 393-406. (https://doi.org/10.1007/s00281-018-0670-4)

Xu Y, Plazyo O, Romero R, Hassan SS \& Gomez-Lopez N 2015 Isolation of leukocytes from the human maternal-fetal interface. Journal of Visualized Experiments $\mathbf{5 2 8 6 3}$ e52863. (https://doi.org/10.3791/52863)

Xu Y, Romero R, Miller D, Silva P, Panaitescu B, Theis KR, Arif A, Hassan SS \& Gomez-Lopez N 2018 Innate lymphoid cells at the human maternal-fetal interface in spontaneous preterm labor. American Journal of Reproductive Immunology 79 e12820. (https://doi.org/10.1111/ aji.12820)

Received 15 November 2019

First decision 18 December 2019

Revised manuscript received 12 February 2020

Accepted 2 March 2020 